OPEN ACCESS

Edited by:

Yoshitomo Kikuchi,

National Institute of Advanced Industrial Science and Technology

(AIST), Japan

Reviewed by:

Tsubasa Ohbayashi,

National Agriculture and Food Research Organization (NARO), Japan

Laura V. Flórez,

Johannes Gutenberg University

Mainz, Germany

${ }^{*}$ Correspondence:

Nicole M. Gerardo

Nicole.gerardo@emory.edu

Specialty section:

This article was submitted to

Microbial Symbioses,

a section of the journal

Frontiers in Microbiology

Received: 01 June 2021

Accepted: 20 August 2021

Published: 04 October 2021

Citation:

Acevedo TS, Fricker GP, Garcia JR, Alcaide T, Berasategui A, Stoy KS and Gerardo NM (2021) The

Importance of Environmentally

Acquired Bacterial Symbionts for the Squash Bug (Anasa tristis),

a Significant Agricultural Pest.

Front. Microbiol. 12:719112.

doi: 10.3389/fmicb.2021.719112

\section{The Importance of Environmentally Acquired Bacterial Symbionts for the Squash Bug (Anasa tristis), a Significant Agricultural Pest}

Tarik S. Acevedo ${ }^{1}$, Gregory P. Fricker ${ }^{1}$, Justine R. Garcia ${ }^{1,2}$, Tiffanie Alcaide ${ }^{1}$, Aileen Berasategui ${ }^{1}$, Kayla S. Stoy ${ }^{1}$ and Nicole M. Gerardo ${ }^{1 *}$

${ }^{1}$ Department of Biology, Emory University, Atlanta, GA, United States, ${ }^{2}$ Department of Biology, New Mexico Highlands University, Las Vegas, NM, United States

Most insects maintain associations with microbes that shape their ecology and evolution. Such symbioses have important applied implications when the associated insects are pests or vectors of disease. The squash bug, Anasa tristis (Coreoidea: Coreidae), is a significant pest of human agriculture in its own right and also causes damage to crops due to its capacity to transmit a bacterial plant pathogen. Here, we demonstrate that complete understanding of these insects requires consideration of their association with bacterial symbionts in the family Burkholderiaceae. Isolation and sequencing of bacteria housed in the insects' midgut crypts indicates that these bacteria are consistent and dominant members of the crypt-associated bacterial communities. These symbionts are closely related to Caballeronia spp. associated with other true bugs in the superfamilies Lygaeoidea and Coreoidea. Fitness assays with representative Burkholderiaceae strains indicate that the association can significantly increase survival and decrease development time, though strains do vary in the benefits that they confer to their hosts, with Caballeronia spp. providing the greatest benefit. Experiments designed to assess transmission mode indicate that, unlike many other beneficial insect symbionts, the bacteria are not acquired from parents before or after hatching but are instead acquired from the environment after molting to a later developmental stage. The bacteria do, however, have the capacity to escape adults to be transmitted to later generations, leaving the possibility for a combination of indirect vertical and horizontal transmission.

Keywords: symbiosis, Coreidae, Cucurbit Yellow Vine Disease, squash bugs, Caballeronia

\section{INTRODUCTION}

Microbial symbionts can increase their hosts' fitness by provisioning them with nutrients or by protecting them against pathogens, parasites, and predators (Moran, 2006; Haine, 2008; Gerardo and Parker, 2014). Association with microbial symbionts, therefore, significantly alters the ecology of most hosts, which can have important applied implications when those hosts are significant pests or are vectors of disease. Indeed, some suggested methods for future control of pest and disease 
vectors rely on alteration of the host-symbiont association (Douglas, 2007; Chuche et al., 2016; Mendiola et al., 2020).

The squash bug, Anasa tristis De Greer (Heteroptera: Coreidae; Figure 1A), is a devastating plant pest of the Cucurbitaceae family (Beard, 1940; Cook and Neal, 1999), preferentially feeding on squash and pumpkins (Nechols, 1987; Bonjour and Fargo, 1989). As sap-feeders, the bugs pierce plant tissue and cause damage to xylem transport (Neal, 1993). Furthermore, A. tristis is a natural reservoir and vector of the bacterium Serratia marcescens, the causal agent of Cucurbit Yellow Vine Disease (CYVD) (Avila et al., 1998; Bruton et al., 1998, 2003). Like many other species in the order Heteroptera, A. tristis possesses terminal midgut structures (Figures 1B-D and Supplementary Figure 1), known as crypts or ceca. The crypts house bacterial symbionts in other heteropteran species (Fukatsu and Hosokawa, 2002; Kikuchi et al., 2005, 2011a; Olivier-Espejel et al., 2011; Boucias et al., 2012; Garcia et al., 2014; Itoh et al., 2014; Ohbayashi et al., 2015; Takeshita et al., 2015). In many families within the Coreoidea and Lygaoidea, and in the Largidae family within the Pyrrhocoroidea, the predominant symbionts within the crypts are bacteria from the Burkholderiaceae (Kikuchi et al., 2005, 2011a; Olivier-Espejel et al., 2011; Boucias et al., 2012; Garcia et al., 2014; Itoh et al., 2014; Sudakaran et al., 2015; Takeshita et al., 2015; Gordon et al., 2016; Xu et al., 2016a; Ohbayashi et al., 2019b; Ravenscraft et al., 2020). These symbionts most commonly have been referred to as Burkholderia, though evidence supports reclassification of these symbionts into the genus Caballeronia (Dobritsa and Samadpour, 2016, 2019; Beukes et al., 2017; Takeshita and Kikuchi, 2020), and hereafter we will refer to them as Caballeronia spp. Other bacteria can inhabit crypts as well. In some species, these bacteria are co-inhabitants with Caballeronia (Fukatsu and Hosokawa, 2002; Boucias et al., 2012; Garcia et al., 2014; Gordon et al., 2016), while in others they are alternatives to a Caballeronia association (Takeshita and Kikuchi, 2020; Nishino et al., 2021).

Caballeronia symbionts can provide their hosts with several benefits. These include faster development, increased survival and reproduction, increased body size, stronger immune-based defense, and insecticide resistance (Kikuchi et al., 2007, 2012; Olivier-Espejel et al., 2011; Boucias et al., 2012; Garcia et al., 2014; Kikuchi and Fukatsu, 2014; Kim et al., 2015; Lee et al., 2017; Itoh et al., 2018). The benefits conferred differ based on the insect species and, in at least one species, based on the bacterial strain (Kikuchi et al., 2012; Itoh et al., 2019; Ravenscraft et al., 2020).

It is well documented that symbionts can alter the life history and food preference of crop pests (Hosokawa et al., 2007; Toju and Fukatsu, 2010), as well as alter transmission of pathogens by insect vectors (Weiss and Aksoy, 2011; Crotti et al., 2012; Su et al., 2013; Arora and Douglas, 2017). It is currently unknown whether A. tristis harbors beneficial bacterial symbionts. Here, we identify the bacteria within the midgut crypts of A. tristis through culture-independent and culturedependent $16 \mathrm{~S}$ rRNA sequencing. We then determine how these bacteria are transmitted between squash bug generations and how they affect host fitness. We demonstrate that crypt communities are dominated by Caballeronia that are predominantly acquired from the environment each generation, leaving the possibility for individual insects to pick up strains with alternative fitness traits. Controlled infection experiments demonstrate that association with these bacteria can significantly increase host survival and decrease development time, and that bacterial strains vary in their ability to colonize and provide benefits to their hosts. Taken together, these data suggest that these bacteria are a primary, beneficial symbiont of these agricultural pests and vectors of plant disease.

\section{MATERIALS AND METHODS}

\section{Characterization of Crypt Bacterial Community Through Culture-Independent Sequencing}

A. tristis adults were collected from Crystal Organic Farm in Georgia, United States from crookneck squash plants (Cucurbita реро) in the summer of 2014. Insects were transported to the laboratory and either dissected immediately or housed with plant material and conspecifics from their collection site until dissection. Squash bugs were anesthetized with $\mathrm{CO}_{2}$ gas, sacrificed, surface-sterilized in 95\% ethanol for $5 \mathrm{~min}$ and rinsed in sterile Carlson's solution (Mitsuhashi, 2002). We dissected the midgut from 10 adults: the M1 and M4 organs from the midgut were collected from five adults, and the entire midgut was dissected from the remaining five adults. These tissues were rinsed with Carlson's solution and then crushed with a micro-pestle in Carlson's solution. DNA was extracted from each sample using a cetyl trimethylammonium bromide (CTAB) protocol. Specifically, an equal volume of CTAB was added to each sample and then incubated at $60^{\circ} \mathrm{C}$ for $1 \mathrm{~h}$. Sodium dodecylsulfate (SDS) was added to a final concentration of $2 \%$, and samples were incubated at $60^{\circ} \mathrm{C}$ for $1 \mathrm{~h}$. Nucleic acids were extracted with an equal volume of 24:24:1 phenol:chloroform:isoamyl alcohol and then extracted twice with an equal volume of chloroform. Two volumes of cold 99.5\% ethanol and 0.1 volume of $\mathrm{NaOAc}$ were added, and then samples were placed at $-20^{\circ} \mathrm{C}$ to precipitate overnight. Pelleted DNA was washed with $75 \%$ ethanol, dried, and re-suspended in molecular grade water.

We surveyed the bacterial microbiome by amplifying the V4 region of the 16S rRNA gene using dual-indexed primers (Kozich et al., 2013). Each primer consisted of an Illumina adapter, index, pad, link and V4-specific sequences. Specifically, the V4 $16 S$ forward primer ( $5^{\prime}$-GTGCCAGCMGCCGCGGTAA-3') was combined with 15 index sequences, and the $\mathrm{V} 416 \mathrm{~S}$ reverse primer (5'-GGACTACHVGGGTWTCTAAT-3') was combined with i7 index sequences. These primers resulted in a $250 \mathrm{bp}$ amplicon. The 5 PRIME MasterTaq PCR kit was used to amplify the V4 region of the $16 \mathrm{~S}$ rRNA gene in $25 \mu \mathrm{L}$ reactions containing final concentrations of $0.5 \times 5$ PRIME MasterTaq Buffer with $\mathrm{Mg}^{2+}, 200 \mu \mathrm{M}$ dNTPs, $400 \mathrm{nM}$ each forward and reverse primers, $1 \times$ Taqmaster PCR enhancer, $1 \mathrm{mM} \mathrm{MgCl}_{2}, 1 \mathrm{U}$ Taq polymerase and genomic DNA. Reactions were denatured at $94^{\circ} \mathrm{C}$ for 2 min followed by 30 cycles of: (1) $94^{\circ} \mathrm{C}$ for $20 \mathrm{~s}$, (2) 

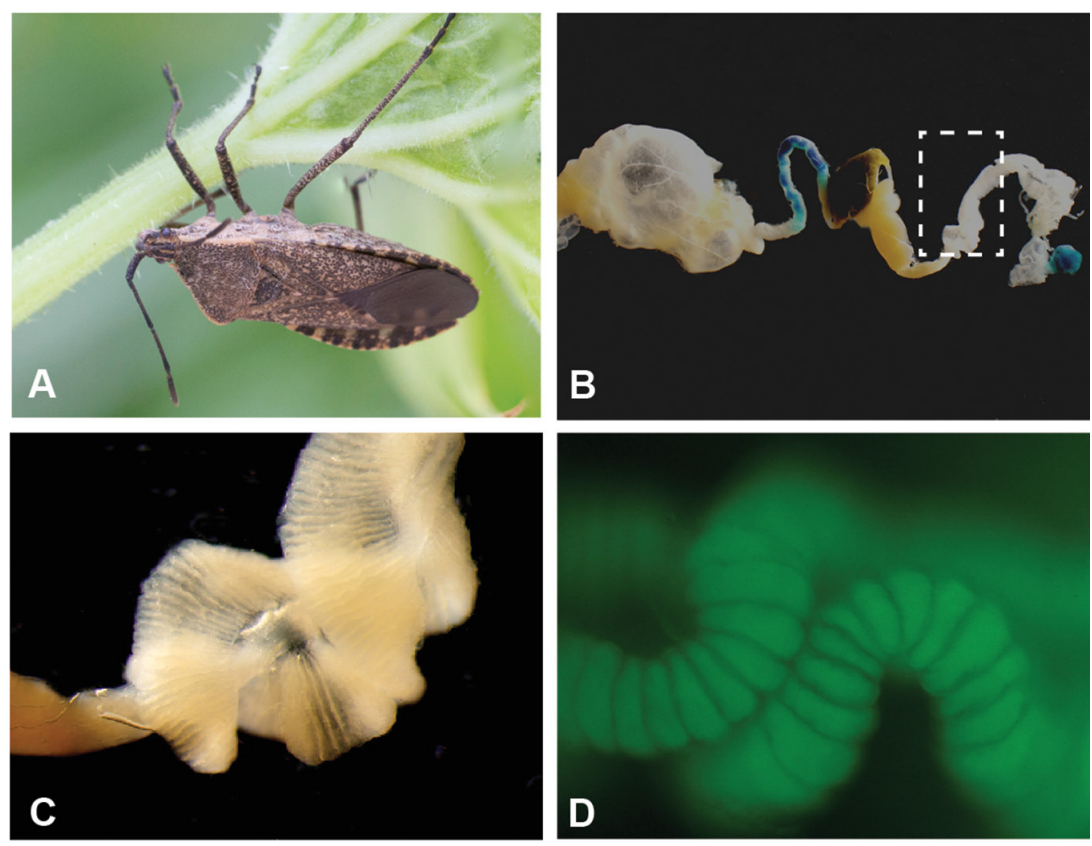

FIGURE 1 | Specialized midgut crypts of the agricultural pest Anasa tristis. (A) Adult $A$. tristis. (B) Entire midgut of adult $A$. tristis, with box highlighting M4 section. (C) Close-up of M4 section, which has the highly invaginated surface typical of midgut symbiont crypts in other true bug species. (D) Close up of crypts with GFP-labeled Caballeronia sp. bacteria. Additional images in Supplementary Figure 1.

either 55 or $60^{\circ} \mathrm{C}$ for $15 \mathrm{~s}$, (3) and $72^{\circ} \mathrm{C}$ for $5 \mathrm{~min}$, with a final elongation step at $72^{\circ} \mathrm{C}$ for $10 \mathrm{~min}$. Amplicons were purified with the Qiagen PCR Purification kit, eluted with molecular grade water, and quantified with the Qubit dsDNA BR Assay kit using the Qubit Fluorometer. Samples were pooled in equimolar concentrations and then run on an Illumina MiSeq with the MiSeq Reagent Kit v2.

MiSeq data were analyzed following a standard pipeline (Kozich et al., 2013) in mothur (Schloss et al., 2009). Paired-end reads were assembled into contigs and screened to remove contigs that were the wrong length, had ambiguous reads or had more than eight homopolymers. The remaining contigs were dereplicated, aligned to sequences from the non-redundant SILVA database (release 119), and pre-clustered into OTUs using a 97\% similarity threshold. Chimeras (identified by VSEARCH) were removed. Sequences were taxonomically classified using the Wang method with template sequences from the Ribosomal Database Project (training set 18 released June 2020). Sequences identified as archaea, eukaryote, mitochondria, or chloroplast were removed, and the remaining sequences were clustered into phylotypes based on their genus-level classification, the lowest taxonomic classification available for the majority of phylotypes. Phyloseq was used to visualize MiSeq data, and vegan was used to perform Permutational MANOVA (PERMANOVA) statistical tests using Jaccard distance with 10,000 permutations. Sampling depth, accession number, and other characteristics for each library are reported in Supplementary Table 1. These data are associated with BioProject PRJNA749731.

\section{Bacterial Isolation and Identification via Culture-Dependent Sequencing}

A. tristis nymphs and adults were collected from plots containing squash and zucchini plants in six states within the United States (Arizona, Indiana, Florida, Georgia, Missouri, and North Carolina). Insects were transported to the laboratory and either immediately dissected or housed with plant material and conspecifics from their collection site until dissection. We dissected midgut crypts (the M4 section of the A. tristis midgut; Figure 1B and Supplementary Figure 1) from 55 adults, one fifth instar, two fourth instars, and two third instars. We then crushed the crypts in either Carlson's solution or $1 \times$ Phosphate Buffered Saline (PBS). One whole second instar nymph was crushed in Carlson's solution, as the midgut was too underdeveloped to dissect. Bacteria were cultivated on Luria-Bertani (LB) agar (incubated for $48 \mathrm{~h}$ at $27^{\circ} \mathrm{C}$ ), a medium on which symbionts from other coreid bugs readily grow (Kikuchi et al., 2007; Garcia et al., 2014). Isolated bacteria were stored as glycerol stocks at $-80^{\circ} \mathrm{C}$.

We used sequencing to identify one to twelve bacterial isolates from each of the 61 bugs sampled. We extracted DNA from bacterial isolates collected prior to 2019 from Georgia and Missouri using a CTAB extraction protocol. Briefly, overnight cultures of each bacterial isolate were lysed by incubating them with $2 \%$ CTAB buffer and $10 \%$ sodium dodecylsulfate (SDS), and then nucleic acids were extracted once with phenol:chloroform:isoamyl alcohol (25:24:1) and twice with chloroform. DNA was recovered by ethanol precipitation at $-20^{\circ} \mathrm{C}$. We extracted DNA from all other bacterial isolates by boiling a single colony of each isolate in molecular-grade water 
$\left(10 \mathrm{~min}\right.$ at $\left.95^{\circ} \mathrm{C}\right)$. We amplified a portion of the $16 \mathrm{~S}$ rRNA gene from each isolate using the MasterTaq ${ }^{\circledR}$ kit (5 PRIME) and universal bacteria primers 27F ( $5^{\prime}$ AGA GTT TGA TCC TGG CTC AG $3^{\prime}$ ) and 1492R (5' GGT TAC CTT GTT ACG ACT T 3') (Lane, 1991). PCR amplifications were performed with an initial $4 \mathrm{~min}$ denaturing at $94^{\circ} \mathrm{C}$, followed by 36 cycles of denaturing for $30 \mathrm{~s}$ at $94^{\circ} \mathrm{C}$, annealing for $30 \mathrm{~s}$ at $55^{\circ} \mathrm{C}$ and extending for $1 \mathrm{~min}$ at $72^{\circ} \mathrm{C}$, with a final $1 \mathrm{~min}$ extension at $72^{\circ} \mathrm{C}$. Amplicons were purified using the QIAquick ${ }^{\circledR}$ PCR Purification Kit and sequenced with the forward primer. All sequences are deposited in Genbank (accession numbers KT259132 KT259191, KX239751 - KX239768, MH636869 - MH636872, and MZ264232-MZ264276). We trimmed the sequences from prior to 2019 using CodonCode Aligner 5.1.5 and all other sequences using SeqMan Pro (DNA STAR Navigator v. 16). Trimmed sequences greater than 500 bps in length were identified to genus through comparison to RDP, the Ribosomal Database Project (training set 18 released June 2020). Information is presented for sequences that had a greater than $60 \%$ match at the genus level. Anasa-derived Burkholderiaceae sequences with a length greater than 580 bps (mean $=844$ bps, median 860 bps), along with additional Burkholderiaceae sequences (see Supplementary Figure 2 for details), were aligned and curated with MAFFT (v 7.407_1) and BMGE (v 1.12.1) as implemented at NGphylogeny.fr (Lemoine et al., 2019). Through NGphylogeny.fr, we used SMS ( $v$ 1.8.1) to estimate the best model of evolution and PhyML (v 3.3.1) to construct a maximum likelihood phylogeny with aLRT-SH branch support (Guindon et al., 2010; Lefort et al., 2017; Ehman et al., 2018). The tree was visualized using Figtree v1.4.2. In order to assess the degree of relatedness between individual strains, a distance matrix was constructed by building a multiple alignment and calculating pairwise identities for each pair of sequences using MUSCLE 3.8.425 (Edgar, 2004) as implemented in Geneious v.2019.2.3.

\section{Symbiont Transmission}

To determine symbiont transmission mode, and for all other experiments, we established colonies of A. tristis in the laboratory. These colonies were originally started by collecting individuals of all instars from gardens and farms in Georgia (United States). Insects are reared in net tents containing multiple pairs of adults and one to two potted squash plants. Plants are changed regularly, and occasionally the colonies are transferred to new tents. Eggs are collected regularly for experiments.

To assess transmission mode, we surface sterilized eggs with a $70 \%$ ethanol wash for $2 \mathrm{~min}$, a $10 \%$ bleach wash for $2 \mathrm{~min}$ and a $10 \mathrm{~s}$ rinse with sterile water. Emerging first instar nymphs were fed on a piece of surface sterilized acorn squash in a bleachcleaned plastic box until they molted to second instar. We then starved the second instars nymphs for $12 \mathrm{~h}$ and gave them access to a parafilm-covered Petri dish $(<20$ nymphs per dish) with sterile water, $1 \%$ blue food-grade dye, which allowed us to assess if the nymphs had fed on the solution, and Green Fluorescent Protein (GFP)-labeled Caballeronia sp. SQ4a (Figure 2) at a concentration of $\sim 10^{7}$ cells $/ \mathrm{mL}$. Caballeronia sp. SQ4a was isolated from an A. tristis adult collected at Oakhurst Garden (Atlanta, Georgia) in 2014 and fluorescently labeled with GFP using a previously described triparental mating protocol (Kikuchi and Fukatsu, 2014). After $24 \mathrm{~h}$, we removed the Petri dish and replaced it with a surface sterilized acorn squash piece for $24 \mathrm{~h}$. To minimize potential exposure to other environmental bacteria, nymphs were then placed into semi-sterile mesh tents ( 12 in $\times 12$ in $\times 12$ in by Raising Butterflies) with axenically grown squash plants. We prepared these semi-sterile environments by: (1) sterilizing the tents and water reservoirs in an autoclave; (2) washing and vortexing each squash seed in $100 \%$ bleach for 5 min; (3) germinating the seeds in sterilized boxes; and, (4) transferring the seeds to autoclaved pots with sterile perlite, a soil substitute. These pots extended into reservoirs filled with sterile water with Botanicare Pure Blend Pro Grow Organic Fertilizer (Supplementary Figure 4). The nymphs were reared in these environments until adulthood.

We then placed these A. tristis adults that had been fed GFPlabeled Caballeronia sp. SQ4a as nymphs into two mesh tents, similar to those described above but with one or two squash plants grown in non-sterile potting soil. The tents contained three to four adults each (two female and two male adults in tent 1; one female and two male adults in tent 2). These adults mated and laid eggs freely. Eggs and nymphs of all developmental stages were periodically removed from both tents to test for the presence or absence of GFP-labeled bacteria. The only mechanism by which these bugs could acquire GFP-labeled bacteria is if it was passed directly from a parent or if it escaped a bacteriainoculated adult and then was acquired from the environment. Since the soil and plants were not sterile, individuals had the opportunity to pick up alternative strains of non-GFP-labeled bacteria as well.

We screened for the presence of GFP-labeled bacteria in eggs and nymphs by visualizing GFP-labeled bacterial colonies isolated from eggs and insects reared in the tents. We surface sterilized some eggs and all nymphs by washing each in $99.5 \%$ ethanol for $30 \mathrm{~s}$; both non-sterile and surface sterilized eggs were utilized to determine whether bacteria came from within the egg or from the egg surface. Eggs (two per sample) and first instar nymphs were crushed with a pestle in $200 \mu \mathrm{L}$ of Carlson's solution. Second, third, and fourth instar nymphs were crushed in $300 \mu \mathrm{L}$ of Carlson's solution. We plated 50$100 \mu \mathrm{L}$ of each solution, in triplicate, onto LB agar with $30 \mu \mathrm{g} / \mathrm{mL}$ kanamycin and incubated the plates at $27^{\circ} \mathrm{C}$ for 2 days. We then assessed presence of GFP-labeled colonies using a fluorescent microscope.

To determine whether low numbers of GFP-labeled bacteria could be detected using the above plating method, we washed eggs in bacterial solutions of known concentrations of GFPlabeled Caballeronia and quantified the bacteria on these eggs using the above methods. For each concentration tested, six surface-sterilized eggs were put into a $1.5 \mathrm{~mL}$ tube. We then added $800 \mu \mathrm{L}$ of a solution with a concentration of approximately $5 \times 10^{3}, 5 \times 10^{2}, 5 \times 10^{1}$, or 5 CFUs of SQ4a per $\mu \mathrm{L}$ (concentrations determined by plating three replicates of $2 \mu \mathrm{L}$ of the inoculation solution). After $10 \mathrm{~min}$, eggs were removed from the solution and allowed to air dry. We plated three replicates per sample. We detected bacteria in all samples washed in solutions of more than 5 CFUs per $\mu \mathrm{L}$ (Supplementary Table 2). 
Bacteria isolated from:

Anasa tristis, Arizona, USA

Anasa tristis, Indiana, USA

Anasa tristis, Missouri, USA

Anasa tristis, North Carolina, USA

Anasa tristis, Georgia, USA

Anasa tristis, Florida, USA

Anasa andresii or A. scorbutica, USA

Oother bug species

[]. environment (soil or plant)

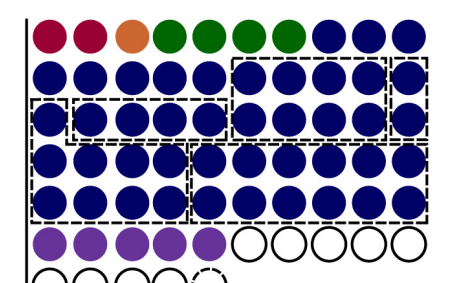

00000

$.92 \mathrm{OOOOO}$

.981000

(1)

92

.

${ }_{95}^{8}$

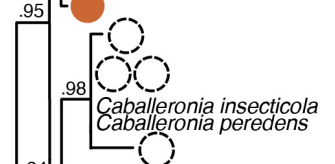



$9200 \mathrm{OSO}$

00

824000

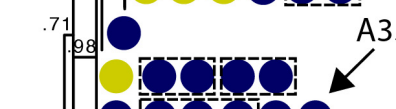

95

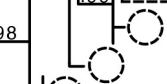<smiles>C1=CC2CCCC[C@@H]2CC1</smiles><smiles>C1CCCC1</smiles>

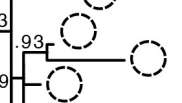<smiles>CC1C2CC3CC(C2)C1C3C</smiles><smiles>C1CC2CCCC2C1</smiles>

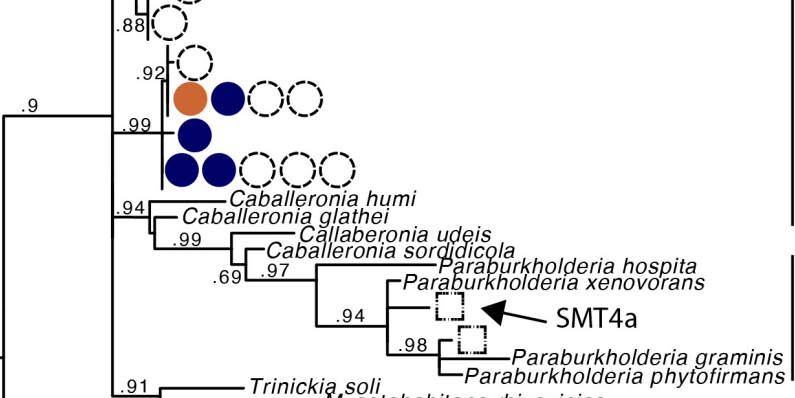

.91 Trinickia soli Burk Burkholderia vietnamier Burkholderia cenocepacia

Burkholderia thailandensis

Ralstonia pickettii

FIGURE 2 | Phylogeny of Caballeronia isolated from squash bug crypts, including symbionts of other true bugs species and other Burkholderiaceae, based on 854 base pair alignment of $16 \mathrm{~s}$ rRNA gene sequences. Dashed lines group isolates within a clade that were isolated from the same individual. Detailed taxa information is provided in Supplementary Figure 2. Arrows point to isolates used for fitness assays. 


\section{Symbiont Uptake and Colonization}

In the above transmission experiment, we did not find GFPlabeled Caballeronia associated with any egg or first instar samples. To determine whether first instars were capable of establishing a Caballeronia infection upon ingestion, we reared first instars from surface sterilized eggs and then exposed them to GFP-labeled Caballeronia sp. SQ4a using several methods. The first method consisted of placing nymphs on a sterile dental cotton roll extending out of a small Petri dish. The dish was filled with bacterial solution, prepared as above, and capped with parafilm. Nymphs were allowed to walk on and probe the resulting saturated cotton for $10 \mathrm{~min}$. The second method consisted of nymphs placed in a small Petri dish with five $2 \mu \mathrm{L}$ droplets of bacterial solution. Only nymphs that were seen probing a droplet were monitored for subsequent symbiont establishment. Similar to the first method, the third method allowed nymphs to walk on bacteria-saturated cotton rolls for $10 \mathrm{~min}$, but they were prodded with a sterile inoculation loop to prevent them from probing the cotton; this method was used to determine if bugs would establish the symbiosis once the bacteria were on the surface of their exoskeleton. As a comparison, we used similar procedures to inoculate second instar nymphs using the first two methods. In total, we exposed 18 first instars and 15 second instars using the "cotton" method, seven first instars and five second instars using the "droplet" method, and seven first instars using the "surface" method. Nymphs were sacrificed after molting to the next instar in order to assay whether they contained any GFP-labeled bacteria using plating methods described above.

To estimate the Caballeronia sp. SQ4a load carried in adults upon establishment, second instar nymphs were reared from surface sterilized eggs and fed GFP-labeled Caballeronia sp. SQ4a using the cotton method detailed above. Individuals were then placed on semi-sterile hydroponic plants, as described above, and reared to adulthood. Once they reached adulthood, we dissected midgut crypts from 10 females and 13 males, and, as described above, dilution plated these samples onto Yeast extract and Glucose (YG) media with IPTG to estimate the total CFUs per crypt that were GFP-labeled.

\section{Fitness Benefits of Symbiosis With a Focal Symbiont for Host When Reared on Plants}

We fed second instar nymphs on a sterile Petri dish with GFP-labeled Caballeronia sp. SQ4a or without GFP-labeled bacteria (water control), using protocols described above. We then replaced the diet with a piece of sterile acorn squash, and fed the inoculated insects on fruit for 1-10 days (mean 4.6 days for bacteria treatment, 4.5 days for control treatment) before moving them to plants. We set up five replicate plant tents (Supplementary Figure 4) with Caballeronia sp. SQ4a inoculated second instars $(n=8,10,11,16,17$ individuals per tent) and six replicate plant tents with water inoculated (control) second instars $(n=6,8,9,10,14,16$ individuals per tent). Insects were reared in a climate-controlled chamber at $28^{\circ} \mathrm{C}(16 \mathrm{~h} \mathrm{~L}: 8 \mathrm{~h} \mathrm{D})$.
Each day, we recorded the number of individuals alive and the developmental stage of live individuals in each tent. We analyzed survival over time as a step function using Kaplan-Meier survival analysis with the "survival" package in $\mathrm{R}$ (Therneau, 2013), and analyzed differences in survival between treatments with mixed effects Cox regression analysis (Klein and Moeschberger, 2003). We censored the data at the time individuals reached adulthood or, in a few cases, when individuals could not be found. We sacrificed adults and confirmed that they either contained (Caballeronia sp. SQ4a treatment) or did not contain (water control treatment) GFP-labeled bacteria in the crypts, using protocols described above. All Caballeroniafed individuals contained GFP-labeled bacteria; no control individuals did.

By monitoring the tents daily, we determined the proportion of insects in each cage that survived and molted to third, fourth, and fifth instars and to adult. These four dependent variables were analyzed separately using quasibinomial distributed Generalized Linear Models (GLMs), with treatment (Caballeronia sp. SQ4a or water-fed controls) as the explanatory factor.

For each individual that survived to a given stage, we estimated development time from: hatch to third instar, hatch to fourth instar, hatch to fifth instar, and hatch to adult emergence. While one would ideally compare the time between each consecutive life stage rather than from hatch to each stage, such data were not estimable based on our counting methodology, and we recognize that these variables are overlapping and therefore correlated. These four dependent variables were analyzed separately using Wilcoxon rank sum tests, with treatment as the explanatory factor. We conducted all statistical analyses in $\mathrm{R}$ v3.0.2 (R Core Team, 2013).

\section{Fitness Benefits of Symbiosis With a Focal Symbiont for Host When Reared on Plants versus Fruits}

In the field, squash bugs feed on both plants and fruits. To determine whether host diet could influence the benefits of symbiosis, we reared sterile first instar nymphs by surface sterilizing eggs as described above. We fed emerging first instar nymphs on surface sterilized zucchini squash until they molted into the second instar. Upon molting, nymphs were randomly distributed into two treatments: (i) Caballeroniainfected or (ii) uninfected control. Bacterial infection was carried out with unlabeled Caballeronia sp. SQ4a, following the "cotton" method described above. Non-infected nymphs were fed water as a control. Following the infection treatment, nymphs were further divided into two new groups representing two different feeding substrates, plant and fruit. This resulted in an experimental design with four treatments: (i) Caballeroniainfected nymphs on plants $(n=41)$, (ii) Caballeronia-infected nymphs on fruit $(n=38)$, (iii) non-infected nymphs on plants ( $n=41$ ), and (iv) non-infected nymphs on fruit $(n=38)$. Nymphs in the plant treatment were reared in groups of 8 15 on squash plants growing in nutrient water within mesh tents as described above. Nymphs in the fruit treatment were placed in groups of not more than 10 individuals in 
plastic boxes containing a piece of surface-sterilized acorn squash. Each treatment was conducted in quadruplicate. The experiment ran for 29 days in a climate-controlled chamber at $28^{\circ} \mathrm{C}(16$ h L:8 h D).

Fitness was assessed by monitoring the tents and boxes daily and measuring the same fitness parameters described above. Statistical analyses were carried out as described above for analysis of survival and proportion to each instar data, with infection treatment (Caballeronia sp. SQ4a or water-fed controls) and food substrate (plant or fruit) as explanatory factors. Development time from hatch to each instar was analyzed using quasipoisson distributed Generalized Linear Models (GLMs); as above, this was done separately for the time to third instar, fourth instar, fifth instar and adult. Tukey's post-hoc tests were used to calculate differences between the groups using the R package "multcomp" (Bretz et al., 2010).

\section{Variation in Fitness Benefits Conferred by Alternative Bacteria}

Second instar nymphs ( $n=60-76$ per treatment) were fed one of four different GFP-labeled bacterial strains (SQ4a, A33_M4_a, SMT4a, BHJ32i) or a water control, using methods described above. A33_M4_a is a Caballeronia sp. isolated from the crypt of an adult $A$. tristis from Crystal Organic Farm (Newborn, Georgia, United States), and SMT4a is a Paraburkholderia sp. (Burkholderiaceae), isolated from soil at a site with other Caballeronia-associated true bug species in the genus Alydus (Garcia et al., 2014). BHJ32i, a Cupriavidus sp. (Burkholderiaceae), was isolated from the M4 crypts of an Alydus tomentosus adult (Garcia et al., 2014) all strains are indicated in Figure 2. Hereafter, for brevity, treatments are referred to as "SQ4a," “A33," "SMT," "BHJ," and "H2O.” After a 24 h rest period following bacterial feeding, nymphs were placed in sterilized boxes (five nymphs per box) with surface sterilized zucchini squash. Development was recorded daily, and the fruit was replaced daily. Upon reaching the adult stage, recently molted adults were weighed and photographed. From photographs, we estimated four measures of body size (scutellum width, pronotum width, posterior tibia length, and body length) using ImageJ. Live adults were then isolated from one another. Adults that died before being dissected were also weighed and imaged for size measurements within $24 \mathrm{~h}$ of dying. To quantify bacterial load, adults were dissected as previously described 2-5 days after molting, and their crypts were crushed with a pestle in $500 \mathrm{uL}$ Carlson's solution. Serial dilution was performed in LB broth, and cells were plated onto YG + IPTG plates. GFP colony forming units in the crypts were estimated from two replicate plates at the most appropriate serial dilution. Statistical analyses of survival and development data were carried out as described above. Log-transformed pronotal width, square root-transformed adult weight data and log-transformed colony forming unit data were analyzed with ANOVAs, with sex and bacterial inoculation treatment as factors. Tukey's multiple comparisons were used to further assess the impacts of bacterial treatment on pronotal width and on bacterial colonization.

\section{RESULTS}

\section{Characterization of Crypt Bacterial Community Through Culture-Independent Sequencing}

We analyzed an average of 101,191 quality-filtered reads per sample for four M1 samples, five M4 samples, and five whole midgut samples (Supplementary Table 2). After trimming and quality control, the median read length was $253 \mathrm{bp}$ (min: 238 bp, max: 259 bp). Caballeronia was the main constituent of the midgut crypts (M4) in four of the five adult squash bugs we sampled (Figure 3A) and accounted for an average of $68.0 \%$ of the MiSeq reads recovered from the crypts. The crypts of one insect, SBA.36, were instead dominated by unclassified Enterobacterales reads $(80.4 \%)$, but unclassified Burkholderiaceae reads were the second most abundant phylotype (17.5\%) in this sample. Caballeronia was also present in the M1 and whole midgut samples, but at lower relative levels than in the crypts (Figure 3B). The microbiomes of the M1 and M4 organs were significantly different (PERMANOVA, $F=2.65$, d.f. $=1, P=0.039)$.

\section{Bacterial Isolation and Identification via Culture-Dependent Sequencing}

From 61 A. tristis individuals, we isolated one or more bacterial colonies from which we sequenced a portion of the 16s rRNA gene. Of the 128 bacteria sequenced and identified to genus, 114 were identified as Caballeronia (Supplementary Table 3). The remaining sequences were identified as Acinetobacter, Bacillus, Enterococcus, Klebsiella, Paenibacillus, Pseudomonas, Serratia, Staphylococcus, and Stenotrophomonas (Supplementary Table 4). Most of these non-Caballeronia isolates were recovered from M4 crypt samples, though the Serratia isolates were from a whole body, second instar nymph sample and thus may or may not have been living within the crypts. Both Caballeronia and nonCaballeronia species were sequenced from the midgut crypts of five individuals.

We estimated a phylogeny with the Caballeronia 16S rRNA sequences from $A$. tristis, as well as 16S rRNA sequences of representatives of the genera Paraburkholderia and Burkholderia. All 114 A. tristis Caballeronia sequences grouped with Caballeronia isolated from the midguts of other bug species and from plants (Figure 2 and Supplementary Figure 2). Pairwise sequence identity revealed that many of the A. tristis Caballeronia sequences clustered within well-supported clades often comprised of symbionts isolated from broad geographic regions and occasionally containing symbionts isolated from other bug species (Supplementary Figure 3 and Supplementary Table 5). Of the 20 individuals from which we sequenced two or more Caballeronia isolates, six had detectable Caballeronia co-infection with bacteria from two or more sequence groups (Supplementary Table 6), though it is important to note that the portion of the 16s rRNA gene sequenced here is highly similar (>98\% pairwise identity) across almost all Anasa-derived samples, so this result should be interpreted with caution. 


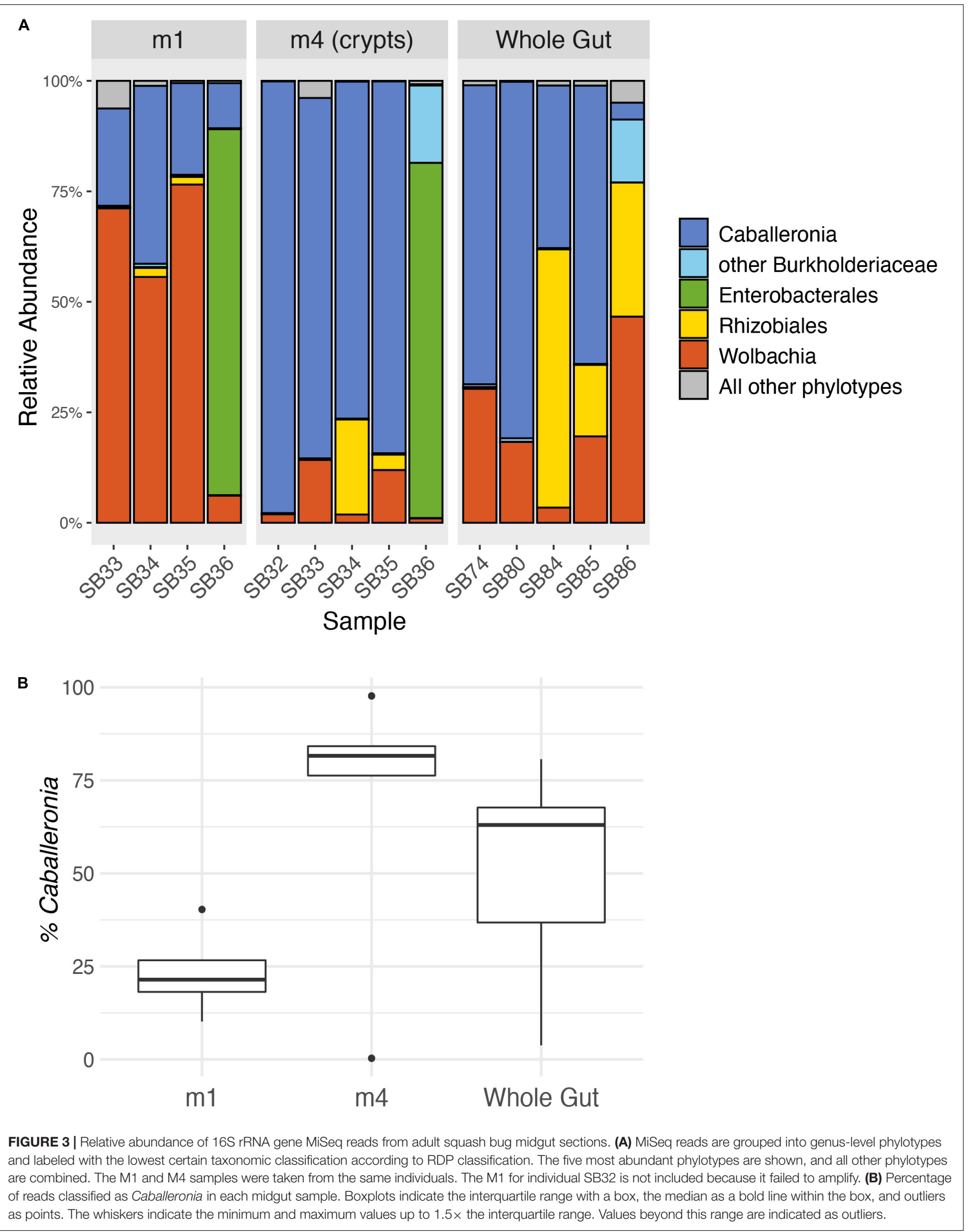




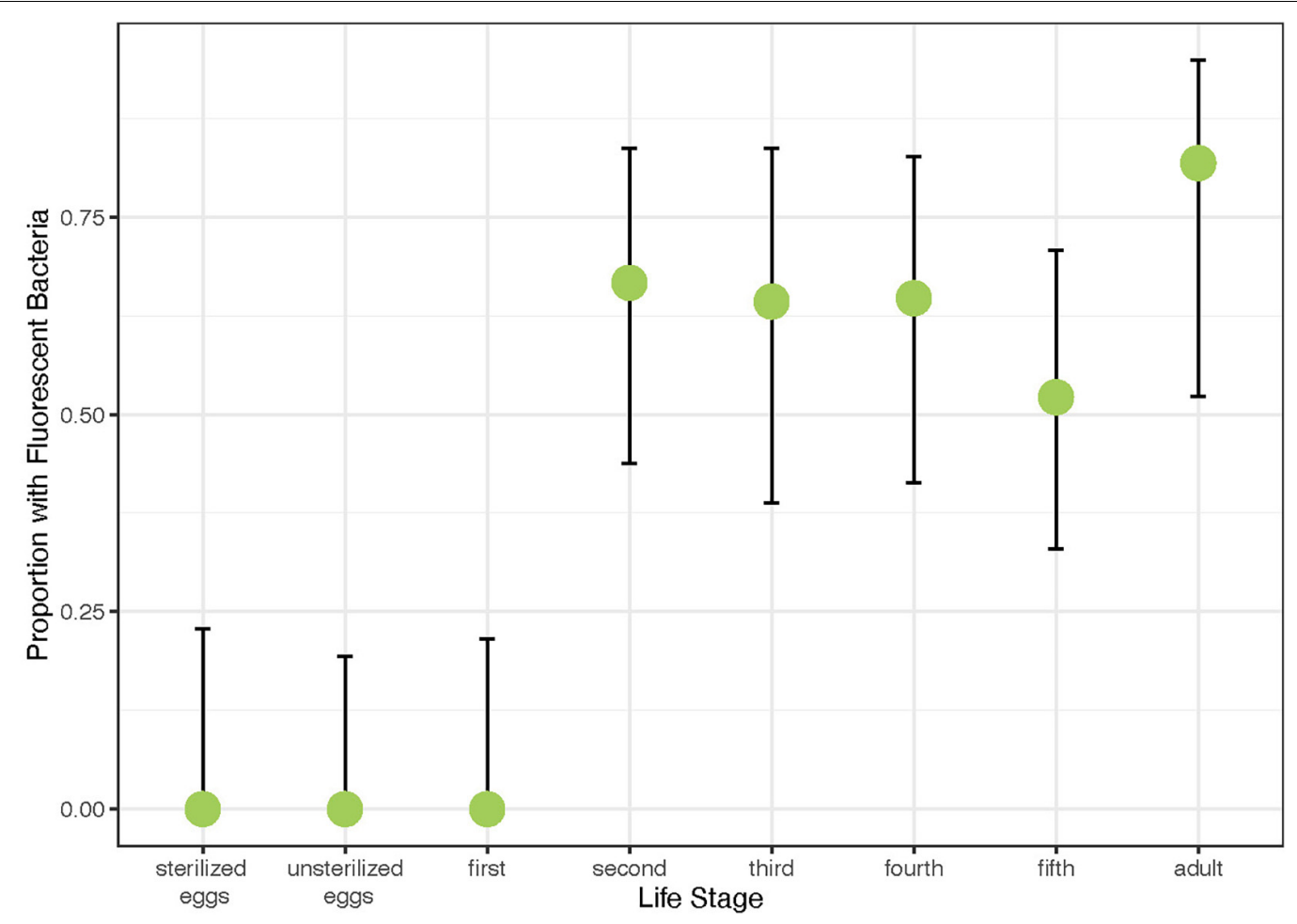

FIGURE 4 | Proportion of offspring of different life stages harboring GFP-labeled Caballeronia sp. SQ4a when reared on plants with parents previously inoculated with GFP-labeled Caballeronia sp. SQ4a. Error bars are binomial confidence intervals. Sample sizes are 13 sets of two sterilized eggs, 16 sets of two unsterilized eggs, 14 first instar nymphs, 18 second instar nymphs, 14 third instar nymphs, 17 fourth instar nymphs, 23 fifth instar nymphs, and 11 adult offspring.

Furthermore, co-infection may be more common than detected given our sampling strategy (i.e., propagation and sequencing of only a few isolates per individual and only a portion of a single gene).

\section{Symbiont Transmission}

In order to determine how Caballeronia are transmitted and acquired, we inoculated a generation of $A$. tristis with GFPlabeled Caballeronia sp. SQ4a and let them mate freely in a nonsterile environment with plants and soil. We then screened their offspring for the presence of the fluorescent Caballeronia. No fluorescent Caballeronia were found on or within eggs or in first instar nymphs. Via isolation and plating, fluorescent Caballeronia were recovered from $50-75 \%$ of second, third, fourth, and fifth instar nymphs, as well as adult offspring (Figure 4). Consistent with this result, using a fluorescent microscope, visualization of whole crypts dissected from adult offspring indicated that 11 of 15 crypts examined were colonized by GFP-labeled bacteria; five of six examined crypts from fifth instars were colonized. Given the substantial fitness benefits of Caballeronia association (see below), we presume that many individuals that made it to later instars without GFP-labeled Caballeronia may have picked up different strains from the plant or soil, neither of which were sterile, as crypts of these individuals often contained other, non-GFP-labeled bacteria that looked morphologically similar to Caballeronia.

\section{Symbiont Uptake and Colonization}

Despite exposure to large numbers of bacteria using three different feeding methods, only 5 of 27 first instars exposed to Caballeronia established Caballeronia infections. In comparison 20 of 20 second instar nymphs fed using similar methods established Caballeronia infections (Figure 5). These results are consistent with the transmission experiment, above, in which we found that colonization increased dramatically after bugs molted to the second instar.

Upon reaching adulthood, both males and females were colonized with a large population of Caballeronia sp. SQ4a in their midgut crypts, with populations averaging $3.46 \times 10^{5} \mathrm{CFUs}$ per adult (Supplementary Figure 5). Though we observed that their crypts often appeared to be bigger, females did not harbor significantly more Caballeronia sp. SQ4a than males ( $T$-test on log-transformed data: $t_{d f}=18.94=1.69, P=0.11$ ).

\section{Fitness Benefits of Symbiosis With a Focal Symbiont for Host When Reared on Plants}

In our first assay of the fitness effects of symbiosis with Caballeronia sp. SQ4a, during which individuals were reared on plants, survival to adulthood was significantly higher for insects inoculated with Caballeronia sp. SQ4a than for control insects inoculated with sterile water $\left(\mathrm{X}_{d f=1}^{2}=12.18, P<0.001\right.$; $H R=0.33$, 95\% C.I. $=1.53-5.69$; Figure 6A). The proportion of 


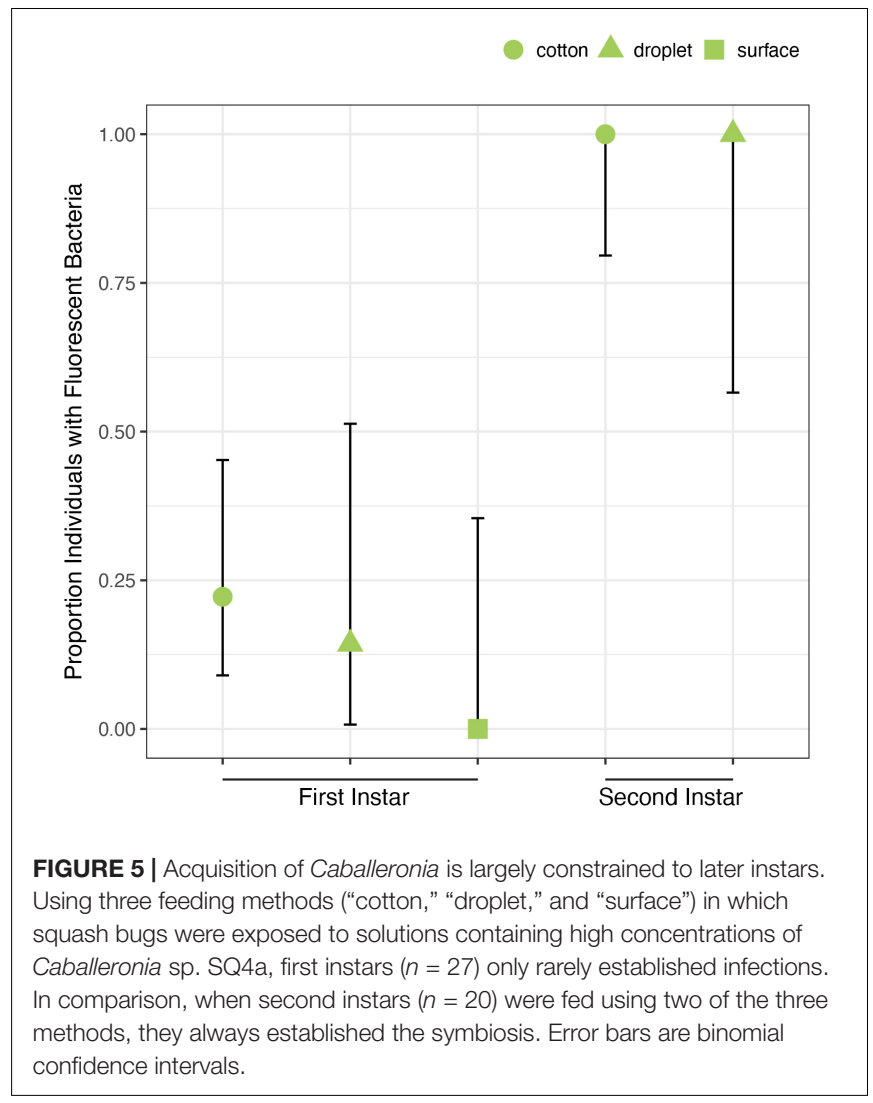

insects surviving and molting to the third instar in Caballeronia sp. SQ4a replicates was not significantly different than those in water (control) replicates $\left(F_{(1,10)}=2.79, P=0.13\right.$, odds ratio $=0.30,95 \%$ C.I. $=-2.87$ to 0.20$)$. Insects inoculated with Caballeronia sp. SQ4a, however, were significantly more likely to survive and molt to the fourth instar $\left(F_{(1,10)}=9.32, P=0.01\right.$, odds ratio $=0.11,95 \%$ C.I. $=-3.78$ to -0.75$)$, fifth instar $\left(F_{(1,10)}=26.65, P<0.001\right.$, odds ratio $=0.05,95 \%$ C.I. $=-4.25$ to -1.72$)$ and into adults $\left(F_{(1,10)}=121.88, P<0.001\right.$, odds ratio $=0.001,95 \%$ C.I. $=-8.26$ to -3.72 ; Figure $6 \mathrm{~B})$. Indeed, no control insects survived and molted into adults. For those insects surviving to the third instar, development time from hatch to third instar was significantly shorter for those inoculated with Caballeronia sp. SQ4a than those inoculated with water $(W=247.00, P<0.001,95 \%$ C.I. $=-3.00$ to -1.00 ; Figure 6C). This was also true for those surviving to the fourth ( $W=52.50$, $P<0.001,95 \%$ C.I. $=-11.00$ to -8.99$)$ and fifth instars ( $W=28.00, P<0.001,95 \%$ C.I. -15.99 to -11.00 ; Figure 6C). Differences in development time from hatch to adult could not be assessed, as no water-inoculated controls survived and molted into adults in this experiment.

\section{Fitness Benefits of Symbiosis With a Focal Symbiont for Host When Reared on Plants versus Fruits}

In our second assay of the fitness effects of symbiosis with Caballeronia sp. SQ4a, during which individuals were reared

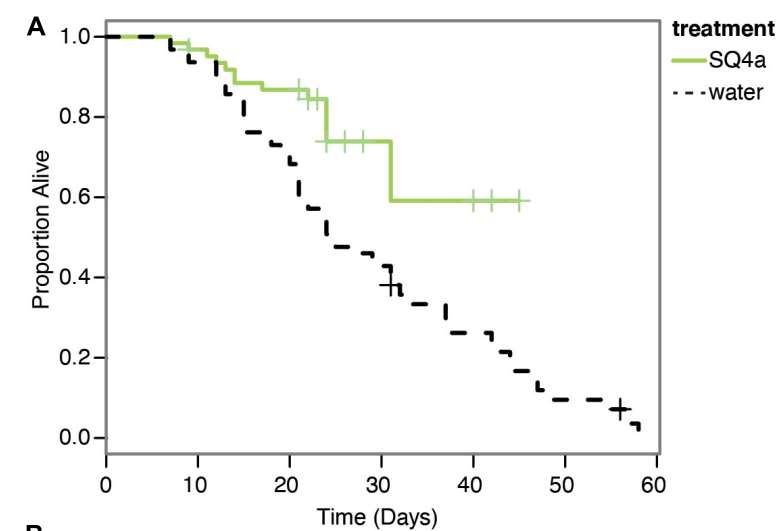

B
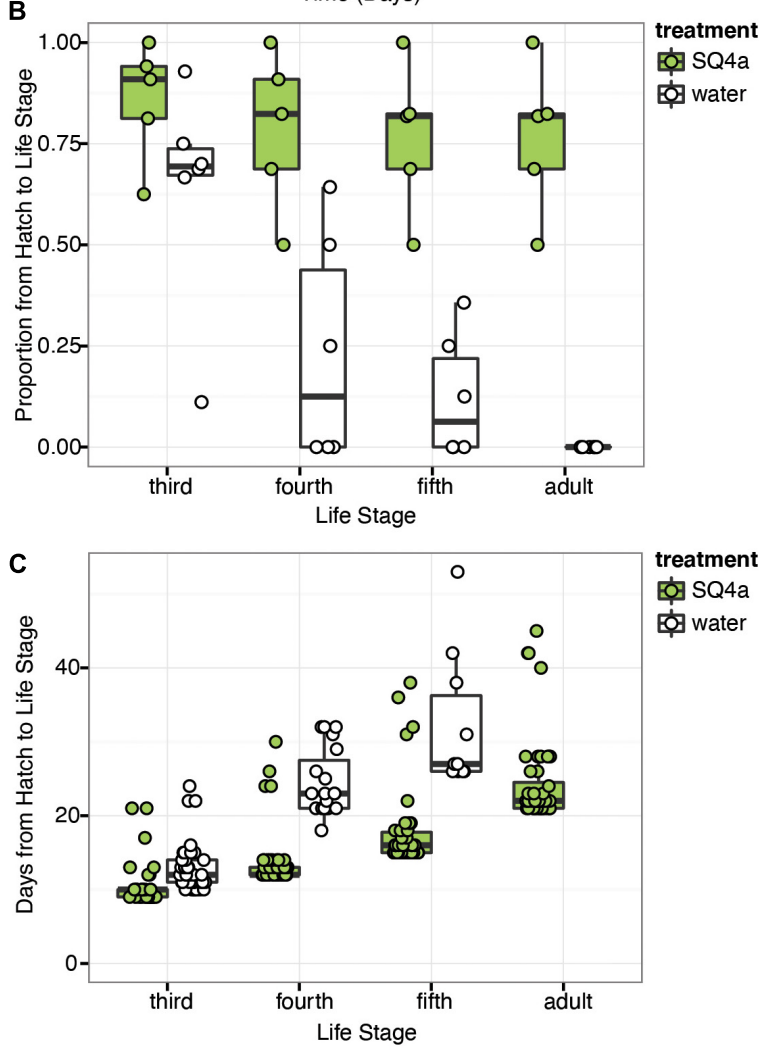

FIGURE 6 | Caballeronia sp. SQ4a association increases survival and decreases development time when squash bugs are reared on plants. (A) Kaplan-Meier survival curves for the Caballeronia inoculation treatment using Caballeronia sp. SQ4a $(n=62)$ and the water (control) $(n=63)$ treatment. Data is censored at the time individuals reached adulthood or, in a few cases, when individuals escaped from cages (indicated by crosses). (B) Proportion of individuals in each tent surviving from hatch to each subsequent life stage. Proportions for each tent are overlaid on box-whisker plots. (C) Development time from hatch to each instar. Points, overlaid on box-whisker plots, indicate estimated development time for each individual that made it to that life stage. In this experiment, no water-inoculated (control) individuals survived to adulthood.

on either plants or fruits, survival to adulthood was higher for Caballeronia-infected insects than non-infected ones, regardless of the feeding substrate (symbiosis: $\mathrm{X}^{2} d f=1=49.67, P<0.001$, $H R=0.17,95 \%$ C.I. $=2.86$ to 11.69 ; substrate: $\mathrm{X}^{2} d f=1=1.74$, 
$P=0.19, H R=1.73,95 \%$ C.I. $=0.18$ to 1.82 ; interaction: $\mathrm{X}^{2} d f=1=0.02, P=0.9, H R=1.08,95 \%$ C.I. $=0.33$ to 2.54 ; replicate: $\mathrm{X}^{2} d f=1=0.42, P=0.51, H R=1.03,95 \%$ C.I. $=0.88$ to 1.06; Figure 7A). We did not find a clear effect of substrate on the proportion of insects that survived from hatching to each instar (Figure 7B). While a higher proportion of Caballeroniainfected nymphs fed on plants versus fruits made it from hatching to third instar $\left(F_{(1,15)}=9.71, P<0.01\right.$, odds ratio $=2.1$, $95 \%$ C.I. $=-0.1$ to 1.62$)$ and to adulthood $\left(F_{(1,15)}=57.62\right.$, $P=0.04$, odds ratio $=3.31,95 \%$ C.I. $=-0.14$ to 2.63$)$, we did not observe such an effect for those that made it from hatching to fourth $\left(F_{(1,15)}=2.55, P=0.14\right.$, odds ratio $=1.51,95 \%$ C.I. $=-0.38$ to 1.22$)$ or fifth instar $\left(F_{(1,15)}=3.1, P=0.10\right.$, odds ratio $=1.47,95 \%$ C.I. $=-0.51$ to 1.3$)$. This pattern suggests that there might be factors driving developmental differences between nymphs feeding on fruits and plants that were unaccounted for (i.e., humidity, cage size, crowding, etc.). However, Caballeronia infection significantly increased the proportion of nymphs that made it from hatching to each developmental stage (third: $F_{(1,15)}=74.67, P<0.001$, odds ratio $=0.43$, 95\% C.I. $=-1.53$ to -0.16 ; fourth: $F_{(1,15)}=147.21, P<0.001$, odds ratio $=0.03$, 95\% C.I. $=-4.72$ to -2.69 ; fifth: $F_{(1,15)}=107.65, P<0.001$, odds ratio $=0.01,95 \%$ C.I. $=-7.00$ to -3.14 ; and adulthood: $F_{(1,15)}=28.14, P<0.01$, odds ratio $=0.05,95 \%$ C.I. $=-8.39$ to -0.71$)$. The proportion of insects that made it to third instar was also affected by the interaction between substrate and Caballeronia infection $\left(F_{(1,15)}=20.69, P<0.001\right.$, odds ratio $=0.09,95 \%$ C.I. $=-3.47$ to -1.35$)$.

Feeding substrate had no effect on the time nymphs took to develop to any life stage except fifth instar, in which case nymphs developed faster on plants versus on fruits (third: $F_{(1,106)}=0.96, P=0.33, O R=1.03,95 \%$ C.I. $=-0.04$ to 0.10 ; fourth: $F_{(1,73)}=2.18, P=0.14, O R=0.99,95 \%$ C.I. $=-0.07$ to 0.05; fifth: $F_{(1,68)}=8.84, p<0.01, O R=0.89,95 \%$ C.I. $=-0.18$ to -0.04 ; and adult: $F_{(1,49)}=10.07, P=0.11, O R=0.95$, $95 \%$ C.I. $=-0.11$ to 0.01 ; Figure 7 C). Caballeronia-infected nymphs had shorter developmental time from hatching to third $\left(F_{(1,106)}=45.61, P<0.001, O R=1.23,95 \%\right.$ C.I. $=0.13$ to 0.28$)$, and fourth instar $\left(F_{(1,73)}=19.56, P<0.001, O R=1.50,95 \%\right.$ C.I. $=0.27$ to 0.53$)$. After fourth instar, infection status no longer impacted developmental time (fifth instar: $F_{(1,68)}=0.66, p=0.42$, $O R=0.92,95 \%$ C.I. $=-0.36$ to 0.18 ; and adulthood: $F_{(1,49)}=9.75$, $P=0.61, O R=1.06,95 \%$ C.I. $=-0.15$ to 0.27$)$; this is likely driven by the fact that very few individuals without symbionts molted to these life stages in the time span of the experiment, which was terminated after 29 days.

\section{Variation in Fitness Benefits Conferred by Alternative Bacteria}

Compared to the two fitness experiments described above, survival to adulthood was much higher in this third fitness experiment. Here, 91\% of Caballeronia-inoculated individuals survived to adulthood, and $84 \%$ of control insects survived to adulthood. In contrast, in our first fitness experiment, $77 \%$ of Caballeronia-inoculated individuals survived to adulthood, and no control insects inoculated with sterile water survived
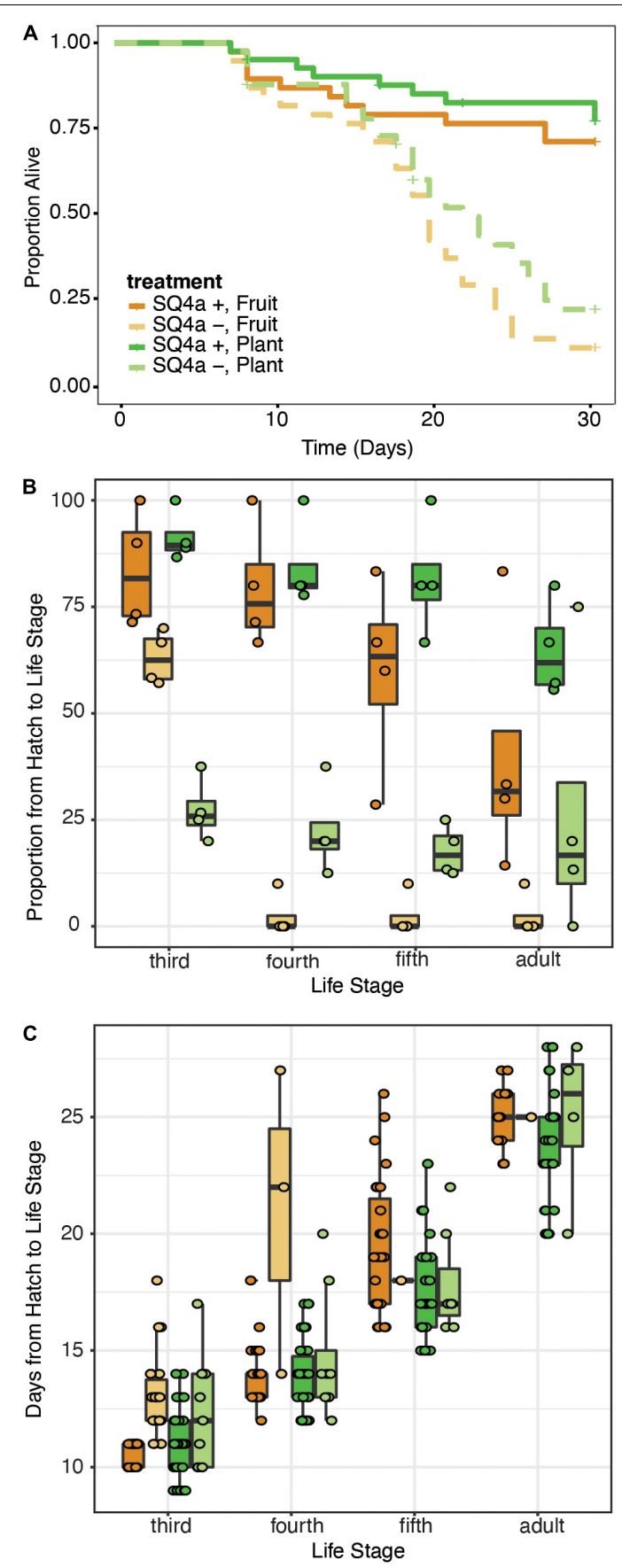

FIGURE 7 | Caballeronia sp. SQ4a association provides similar survival and developmental benefits when squash bugs are reared on plants or fruits. (A) Kaplan-Meier survival curves for Caballeronia-inoculated (solid) and -uninoculated (dashed) treatments when bugs were reared on squash plants (green) and fruits (orange) ( $n=41$ individuals for each plant treatment, and $n=38$ for each fruit treatment). Data is censored after 29 days, at the time individuals reached adulthood or, in a few cases, when individuals escaped from cages (indicated by crosses). (B) Proportion of individuals in each cage surviving from hatch to each subsequent life stage over the course of the 29 day experiment (color scheme as in panel A). Proportions for each cage are overlaid on box-whisker plots. (C) Development time from hatch to each instar (color scheme as in panel A). Points, overlaid on box-whisker plots, indicate estimated development time for each individual that made it to that life stage. 
to adulthood. We hypothesize that these differences are due to optimal rearing conditions for this experiment, in which bugs were at lower population density than the other experiment on fruit, bugs were transferred to new fruit each day, and rearing chambers were cleaned rigorously each day. Under these conditions, there was no significant difference in survival across the five treatments $\left(\chi^{2} d f=4=8.01, P=0.09\right.$; Figure 8A). In terms of proportion of individuals surviving to each instar, all 353 experimental individuals survived to third instar, and most (349 of 353) individuals survived from hatch to fourth instar. There was a significant effect of treatment on the proportion of individuals that made it from hatch to later life stages (fifth: $F_{(4,87)}=4.63, P<0.01$; adult: $\chi^{2} d f=4=85.99, P<0.001$; Figure 8B), though survival to these later life stages too was high.

There were significant differences in development time based on treatment (Figure 8C; hatch to third instar: $F_{(4,351)}=5.30$, $P<0.01$; hatch to fourth instar: $F_{(4,346)}=202.70, P<0.001$; hatch to fifth instar: $F_{(4,336)}=356.33, P<0.001$; hatch to adult: $\left.F_{(4,313)}=236.88, P<0.001\right)$. Notably, development time for individuals inoculated with either Caballeronia sp. SQ4a or A33 was consistently significantly shorter than development time for individuals not inoculated with Caballeronia, while development time for individuals fed $\mathrm{BHJ}$ was not different than that of those not given a symbiont. SMT-inoculated individuals developed significantly faster to the adult stage than individuals not inoculated with Caballeronia, but they developed significantly more slowly than individuals inoculated with SQ4a and A33 (Supplementary Table 7).

Both bacterial treatment and sex significantly influenced adult body size, as measured by the width of the pronotum (Figure 9A; treatment: $F_{(4,182)}=16.05, P<0.001$; sex: $F_{(1,182)}=311.38$, $P<0.001)$. There was no significant interaction of bacterial treatment and $\operatorname{sex}\left(F_{(4,182)}=0.84, P=0.5\right)$. Focusing on bacterial treatments, individuals inoculated with SQ4a and A33 were significantly bigger than individuals fed BHJ, SMT or water (Supplementary Table 8). Qualitatively, sex and treatment had similar impacts on other measurements of body size (i.e., body length, scutellum width, tibia length), as many measurements of Anasa spp. body size are positively correlated (data not shown). In terms of wet weight, just after molting to the adult stage, females were significantly heavier than males (Figure 9B; $\left.F_{(1,251)}=192.58, P<0.001\right)$. Bacterial treatment did not have a significant impact on adult weight $\left(F_{(4,251)}=1.09, P=0.36\right)$, nor was there a significant interaction between sex and treatment $\left(F_{(4,251)}=0.43, P=0.79\right)$.

\section{Colonization by Alternative Bacteria}

The four strains varied in terms of their final loads of GFPlabeled bacteria within the bugs' crypts (Figure 10). Estimated CFUs of SMT in crypts $\left(1.55 \times 10^{7}\right.$ mean CFUs $)$ were higher than estimated CFUs of A33 and SQ4a (means of $1.31 \times 10^{6}$ and $3.46 \times 10^{5}$ CFUs, respectively); all adults screened for these strains were colonized by GFP-labeled bacteria only. BHJ, which is in the genus Cupriavidus, exhibited extremely low colonization (mean $1.23 \times 10^{2} \mathrm{CFUs}$ ) and was recovered from only 3 of 15 sampled adults. For BHJ, colonization should be interpreted with caution; it is possible that recovered GFP-labeled bacteria
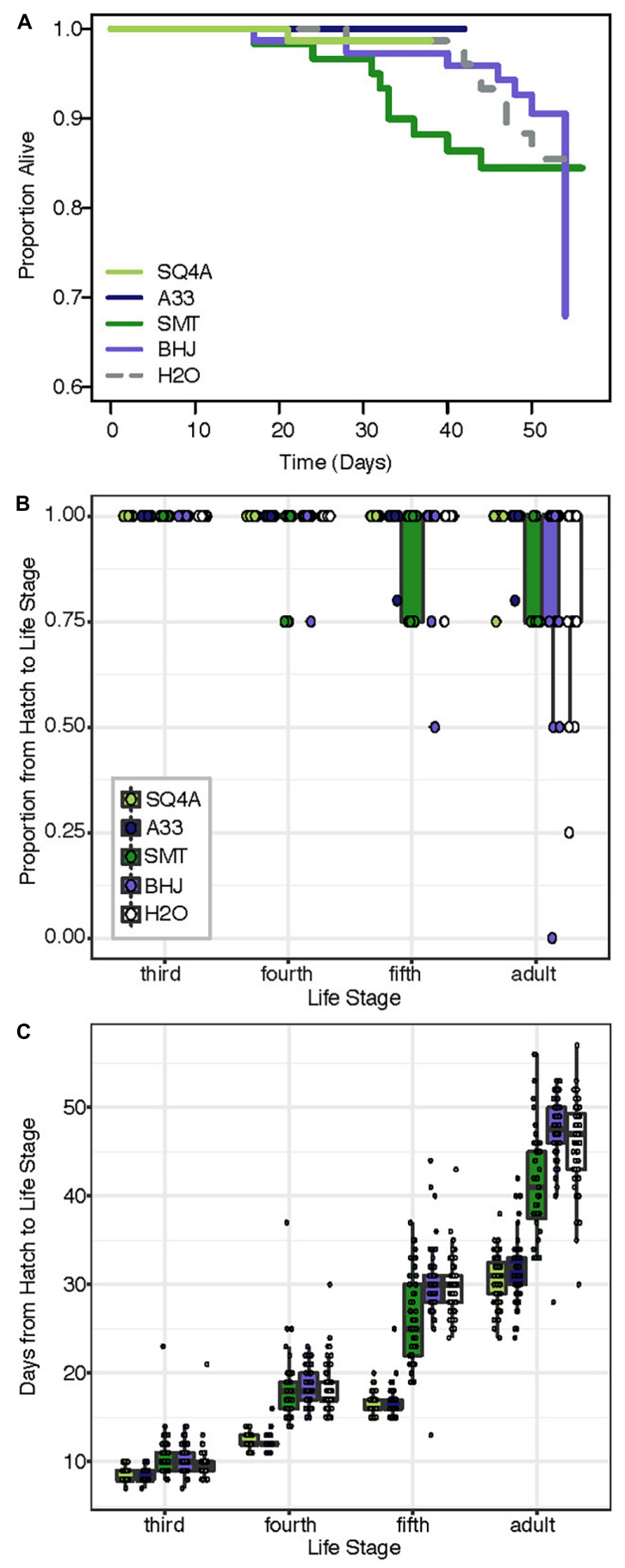

FIGURE 8 | Bacterial strains provide different levels of fitness benefit. Squash bugs were fed either one of two strains of Caballeronia (SQ4a, A33), a strain of Paraburkholderia (SMT), a strain of Cupriavidus $(\mathrm{BHJ})$, or water $(\mathrm{H} 2 \mathrm{O})$ as an un-inoculated control; $n=60-76$ per treatment. (A) Kaplan-Meier survival curves for bacteria-inoculated (solid lines) and un-inoculated (dashed) treatments. Data is censored at the time individuals reached adulthood. (B) Proportion of individuals in each box surviving from hatch to each subsequent life stage. Proportions for each box are overlaid on box-whisker plots. (C) Development time from hatch to each instar (legend in panel B). Points, overlaid on box-whisker plots, indicate estimated development time for each individual that made it to that life stage. 

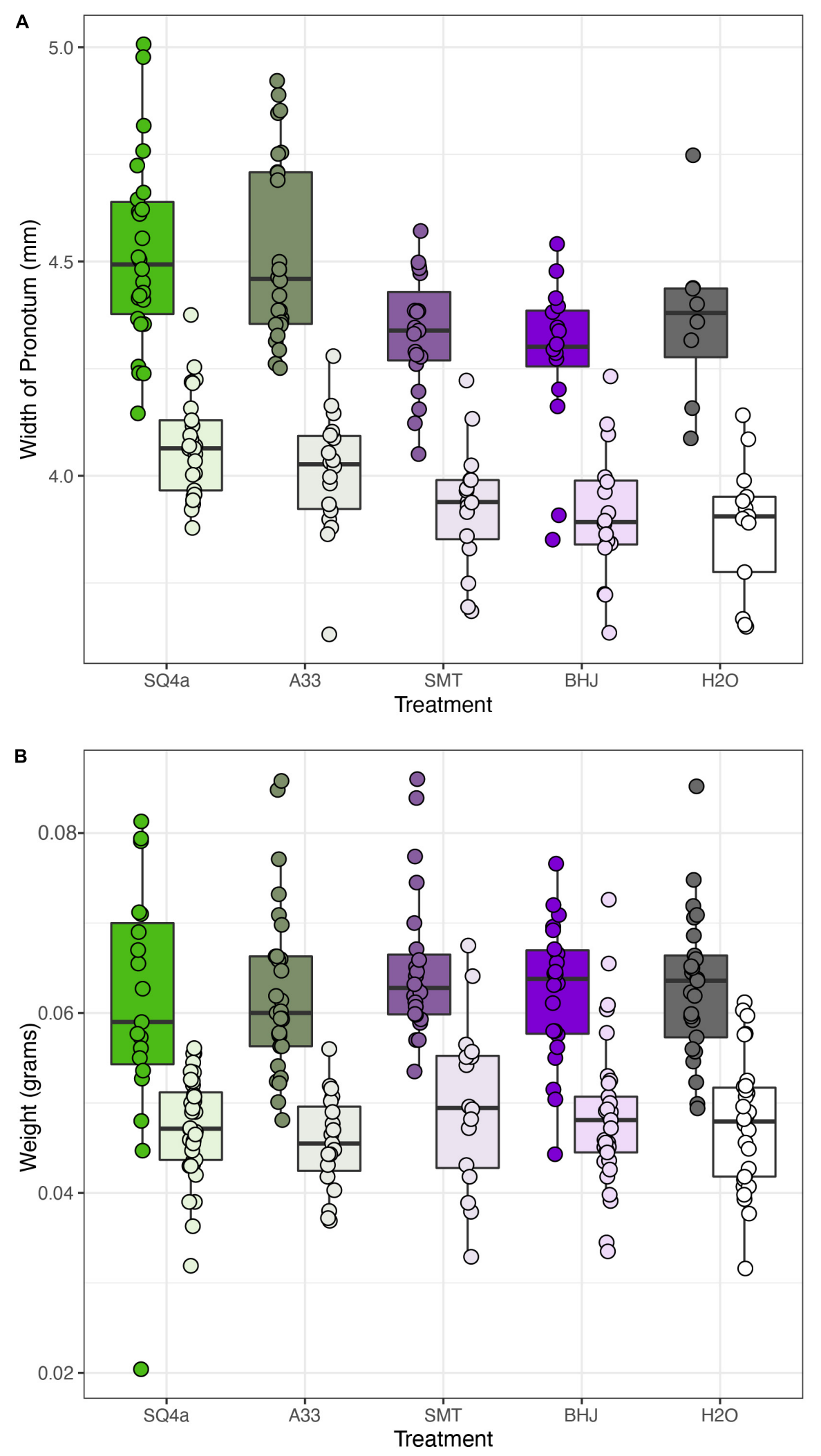

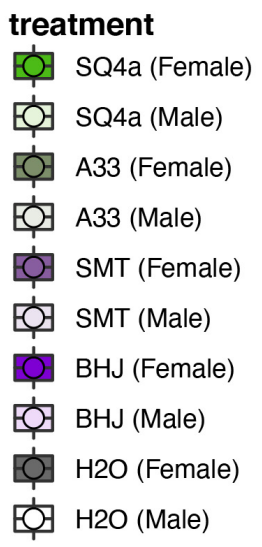

treatment

Of SQ4a (Female)

어 SQ4a (Male)

어 A33 (Female)

A33 (Male)

DI SMT (Female)

ळ. SMT (Male)

BHJ (Female)

아 BHJ (Male)

이 $\mathrm{H} 2 \mathrm{O}$ (Female)

하 H2O (Male)

FIGURE 9 | Bacterial treatment significantly influences size but not weight of adult squash bugs. (A) Based on the width of the pronotum, females were larger than males, and, overall bugs inoculated with SQ4a and A33 were significantly bigger than individuals fed SMT, BHJ, and water. (B) Females were heavier than males, but there was no overall effect of bacterial treatment on adult wet weight. Each point represents the estimate for one individual. 


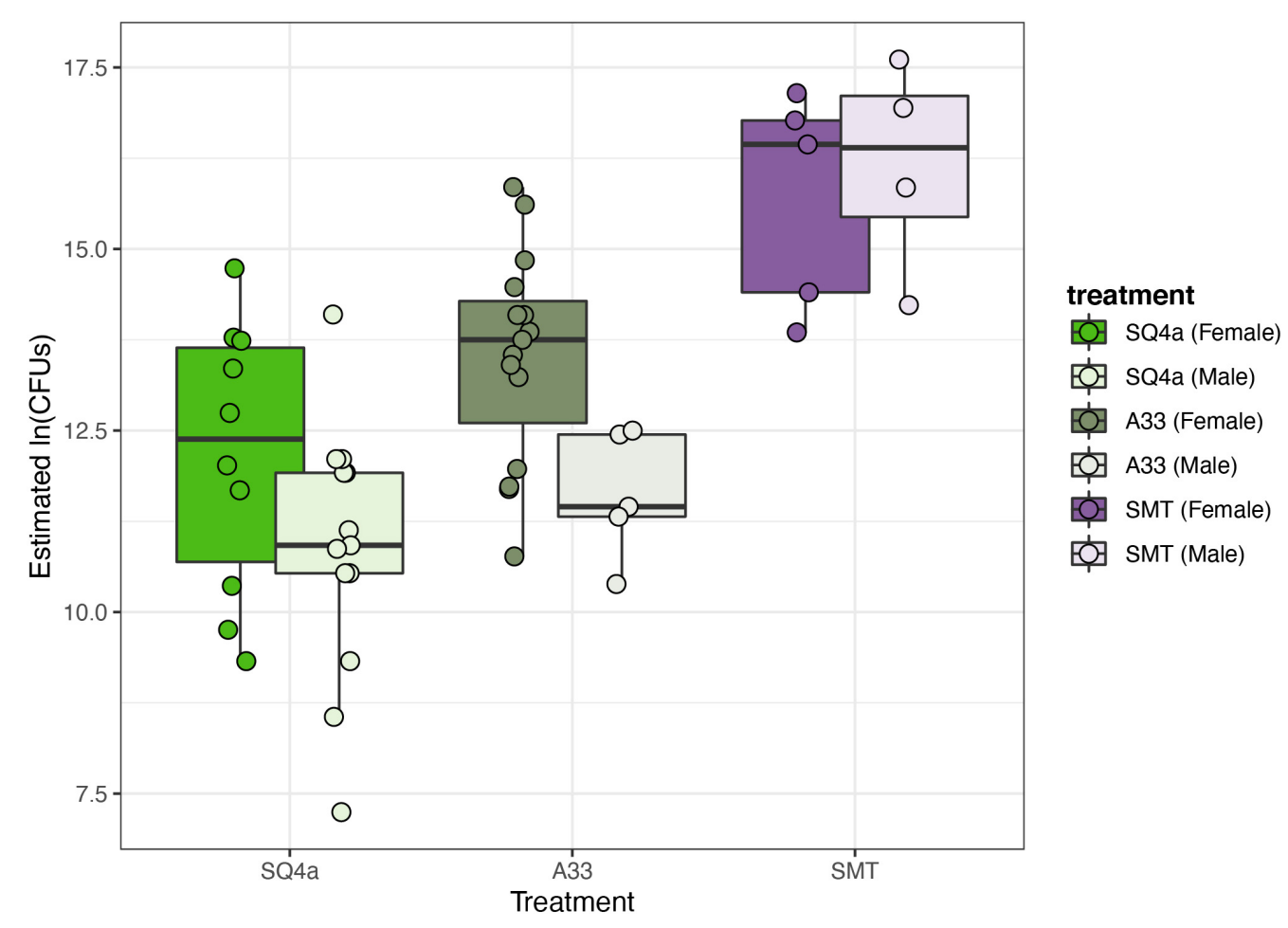

FIGURE 10 | Estimated population sizes of alternative Burkholderiaceae strains in adult crypts. The populations sizes in crypts of the three strains that established in adult bugs differed significantly, with SMT, the Paraburkholderia sp. strain that provided less fitness benefits (Figure 8), establishing the largest populations. Each point represents the estimated population within the M4 crypts of one individual.

were not in the crypts but were contaminants from nearby sections of the gut. No GFP-labeled bacteria were isolated from water-fed controls, and non-GFP labeled bacteria, which were not quantified, never reached high titers. Considering only the three strains that consistently colonized the crypts, differences in final symbiont load were significantly impacted by the bacterial strain $\left(F_{(2,51)}=26.17, P<0.001\right)$, and to a lesser extent by sex $\left(F_{(1,51)}=6.16, P=0.02\right)$; there was no significant interaction between bacterial strain and $\operatorname{sex}\left(F_{(2,51)}=1.56, P=0.22\right)$.

\section{DISCUSSION}

The prevalence of Caballeronia infection and the dominance of Caballeronia in A. tristis' midgut crypt microbial communities suggests that Caballeronia is a symbiont of $A$. tristis, as it is in many bug species (Kikuchi et al., 2005, 2011a; OlivierEspejel et al., 2011; Boucias et al., 2012; Garcia et al., 2014; Itoh et al., 2014; Sudakaran et al., 2015; Takeshita et al., 2015; Gordon et al., 2016; Xu et al., 2016a; Ohbayashi et al., 2019b; Ravenscraft et al., 2020). Experiments varying both the environment and the symbiont strain indicate that the bacteria, which are environmentally acquired, can both increase survival to adulthood and decrease development time, confirming the benefit of Caballeronia-association for these pests. Both sequencing of Anasa-associated Caballeronia and fitness experiments with alternative strains highlight genetic and phenotypic diversity within the system that could have important ecological and evolutionary consequences for the hosts and their symbionts.

Though the bacterial community within a crypt appears to often be dominated by a single Caballeronia strain, there does appear to be occasional co-infections of crypts. Both the culture-independent and culture-dependent approaches indicate that bacteria of other genera can infect the crypts, though at low levels relative to Caballeronia. Furthermore, based on culture-dependent sequencing, which may be limited in its ability to capture co-infections if some strains are recalcitrant to in vitro culturing, a few individuals were determined to be co-infected with multiple Caballeronia strains. The frequency of co-infections is similar to that observed for some Caballeroniaassociated species (e.g., Riptortus pedestris, Blissus insularis) that are rarely co-infected with multiple strains (Boucias et al., 2012). Broad-headed bugs (Alydus spp.) and stilt bugs (Jalysus spp.), however, appear to be co-infected with multiple Caballeronia strains at higher frequencies (Garcia et al., 2014; Ravenscraft et al., 2020). Though some of this variation is likely due to sampling differences, it could also reflect differences in host ecology or physiology that alter the likelihood of co-infection or differences in the ability of the bacteria to outcompete one another (Itoh et al., 2019). Further sampling and experiments will be necessary to understand the environmental and evolutionary factors that contribute to differences in co-infection prevalence across species. Future experiments are also needed to determine 
the impact of crypt co-infection, whether by bacteria of multiple genera or by multiple strains of Caballeronia, on host and symbiont fitness.

An effective and efficient acquisition mechanism is necessary for hosts to maintain a microbial symbiont. Our rearing experiments indicate that Caballeronia sp. SQ4a is not directly passed on to offspring internally or on egg surfaces, which are common routes of vertical transmission, particularly for obligate symbionts, in insects (Salem et al., 2015). Instead, squash bugs acquire Caballeronia expelled from adults via the environment during, and possibly after, the second instar. Environmental acquisition is also largely confined to the second instar in bean bugs (Kikuchi et al., 2011b), indicating that there may be a developmentally confined signal or behavior required for symbiont acquisition in the Coreoidea superfamily of insects, or that there may be morphological or physiological differences between instars that constrain symbiont acquisition to later instars. For example, in the bean bug, $R$. pedestris, the crypts of first instars are rudimentary, which may limit infection potential (Kikuchi et al., 2011b). In experiments in which we know that $A$. tristis first instars probed liquid containing live bacterial cells (i.e., droplet feeding method), we rarely observed establishment, suggesting possible morphological or physiological constraints on symbiont establishment for A. tristis when bacteria are ingested.

In our transmission experiment, which involved tracking of the acquisition of a fluorescently labeled Caballeronia strain, it is unclear from where in the environment the nymphs acquired the bacteria. At the onset, adult squash bugs were the only source of labeled Caballeronia in our rearing experiments, but it is unlikely that nymphs are picking up these bacteria through direct contact with the adults, as such contact appears rare. We hypothesize that Caballeronia are transmitted from parents or other individuals through two potential environmental routes. Caballeronia could be excreted onto plant surfaces or soil with waste products, or they could be transmitted to the surface or internal tissue of the plant as the adults feed, which occurs for other insect symbionts (Gonella et al., 2015; Xu et al., 2016b). Further research will be required to tease apart these alternative routes of environmental acquisition and whether mechanisms of transmission differ based on symbiont strain. Regardless, the fact that the bacteria expelled from adults can be transmitted to the next generation of hosts is consistent with the fact that most individuals we sampled in the field are associated with closely related strains, and suggests a possible combination of horizontal transmission and indirect vertical transmission from parents through an environmental route. Such a transmission route, in which symbionts are escaping into the environment where they are readily picked up by the next generation, may limit some of the negative consequences of vertical transmission, in which population structure imposed by strict host association, coupled with a bottleneck every generation, can lead to symbiont degeneration (O'Fallon, 2008). Environmental acquisition, however, does have risks, as bugs could not acquire a symbiont, or could acquire a less beneficial strain.

Indeed, three separate experiments assessing host fitness highlight the potential risks of not acquiring a Caballeronia symbiont. The symbiosis generally increases host survival, decreases development time and increases the likelihood of transitioning to later instars. While the costs and benefits of symbioses can be contingent on nutrient availability (Faeth and Fagan, 2002; Couret et al., 2019), we found little evidence that feeding on plants versus on fruits, both of which are substrates for $A$. tristis in nature, impacts the pronounced benefits of the symbiosis for these hosts. This suggests that lack of direct vertical transmission is not a consequence of the symbiosis being less necessary in some parts of the growing season, when both fruits and plants are available. That being said, we cannot exclude the possibility of other environmental factors altering the costs and benefits of the symbiosis for these hosts, and, in fact, we do see evidence that rearing conditions that differed across the laboratory experiments did alter the relative benefits of the symbiosis. Whether these differences are relevant in more hostile field conditions is unclear.

We also experimentally demonstrate the possibility for individuals to pick up strains that confer different levels of fitness benefits. In a comparison of insect fitness upon inoculation with one of four different environmental bacterial strains, we find substantial differences in a number of life history traits, including likelihood of molting to adulthood, development time and adult body size. The ability of alternative strains to colonize and provide differential fitness benefits to their hosts has also been shown for $R$. pedestris (Itoh et al., 2019), the best studied Caballeronia-associated true bug species. The variation in benefits may be driven by the metabolic benefits that the bacteria can provide their hosts. Genomic and transcriptomic investigations indicate that the symbiont of $R$. pedestris is involved in carbon, sulfur and nitrogen metabolism. The bacterium also produces all essential amino acids and B vitamins (Ohbayashi et al., 2019a). Whether these are the benefits for $A$. tristis remains to be determined, but the breadth of benefits provided for $R$. pedestris, along with the many bacterial phenotypes that appear necessary for successful host colonization (Kim et al., 2013a,b, 2014; Kinosita et al., 2017), open up the possibility for substantial variation across symbiont strains, particularly if selection acts on these bacteria such that some functions are lost due to relaxed selection or purifying selection when the bacteria are outside of the host. Future research should investigate the bacterial and host factors that underlie variation in symbiotic benefit.

Finally, considering the symbiosis from the perspective of the symbiont, bacterial fitness, as measured by colonization of bug crypts, also varied across bacterial strains used in our study. While the two Caballeronia strains (SQ4a, A33) colonized bugs to a similar level, SMT4a, a Paraburkholderia strain that was less beneficial for the bugs, established significantly larger population sizes in the bugs. Whether these larger populations are costly for the bugs is unclear. It is also unknown whether reaching a larger population size in hosts would increase the likelihood of the bacteria being transmitted to the environment or to other individuals, which may be a better proxy for considering the impacts of host colonization on bacterial fitness. The variation seen across the few strains screened here suggests that the A. tristis system could be used to explore this question. 


\section{CONCLUSION}

In this study, we demonstrate that bacterial communities within midgut crypts of $A$. tristis are dominated by Caballeronia symbionts. Fitness assays on two different substrates suggest that Caballeronia is an essential symbiont of these squash bugs in natural populations. Given that the presence of the symbiont is only detected after molting to the second instar, A. tristis likely acquires the symbiont from the environment. Environmental acquisition, coupled with the fact that bacteria strains vary in the level of fitness benefits that they provide to their hosts, provides an opportunity for these insect pests to acquire bacteria that have alternative phenotypic effects. This opens up the possibility to manipulate the symbiosis in agricultural settings to alter the fitness and/or vector competence of this pest insect and vector of plant disease.

\section{DATA AVAILABILITY STATEMENT}

The datasets presented in this study can be found in online repositories. The names of the repository/repositories and accession number(s) can be found below: https://www.ncbi. nlm.nih.gov/genbank/, KT259132-KT259191; https:/www.ncbi. nlm.nih.gov/genbank/, KX239751-KX239768; https://www. ncbi.nlm.nih.gov/genbank/, MH636869-MH636872; https:// www.ncbi.nlm.nih.gov/genbank/, MZ264232-MZ264276; https: //www.ncbi.nlm.nih.gov/, BioProject PRJNA749731; and https: //doi.org/10.5061/dryad.6tlg1jx04.

\section{AUTHOR CONTRIBUTIONS}

TSA, GPF, JRG, AB, and NMG designed the experiments and analyzed data. TSA, GPF, JRG, TA, AB, and KSS conducted the experiments. All authors contributed to writing and approved the final version of the manuscript.

\section{REFERENCES}

Arora, A. K., and Douglas, A. E. (2017). Hype or opportunity? Using microbial symbionts in novel strategies for insect pest control. J. Insect Physiol. 103, 10-17. doi: 10.1016/j.jinsphys.2017.09.011

Avila, F. J., Bruton, B. D., Fletcher, J., Sherwood, J. L., Pair, S. D., and Melcher, U. (1998). Polymerase chain reaction detection and phylogenetic characterization of an agent associated with yellow vine disease of cucurbits. Phytopathology 88, 428-436. doi: 10.1094/PHYTO.1998.88.5.428

Beard, H. L. (1940). The biology of Anasa tristis DeGeer with particular reference to the tachinid parasite, Trichopoda pennipes Fabr. Bull. Connect. Agric. Exp. Stn. 440, 595-680.

Beukes, C. W., Palmer, M., Manyaka, P., Chan, W. Y., Avontuur, J. R., van Zyl, E., et al. (2017). Genome data provides high support for generic boundaries in Burkholderia sensu lato. Front. Microbiol. 8:1154. doi: 10.3389/fmicb.2017. 01154

Bonjour, E. L., and Fargo, W. S. (1989). Host effects on the survival and development of Anasa tristis (Heteroptera: Coreidae). Environ. Entomol. 18, 1083-1085. doi: 10.1093/ee/18.6.1083

\section{FUNDING}

This research was supported by National Science Foundation grant IOS-1149829 to NMG, USDA NIFA 2019-67013-29371 to NMG, NSF Graduate Research Fellowships to JRG and KSS [grant number DGE-1444932], and a SSE RC Lewontin Early Graduate Research Award to KSS.

\section{ACKNOWLEDGMENTS}

We thank the staff at Crystal Organic Farms, Oxford College Organic Farm, Oakhurst Garden, North DeKalb Community Garden, Front Field Farm, Ten Mother's Farm, Farlow Farm, Merry Lea Sustainable Farm, DeCamp Gardens, and Woodland Gardens, as well as gardeners Sondra Stoy and Dorothy Barse. Special thanks to Nicolas Donck and Daniel Parsons for allowing us to collect samples and for always being supportive of our research. We thank Kent Shelby (University of Missouri), Cindy Goodman, and Joseph Ringbauer for providing samples from the Biological Control of Insects Research Laboratory. We also thank Molly Hunter (University of Arizona), Scott Villa, and Jason Chen for providing samples, and Sandra Mendiola for help with collecting. Additionally, we thank Frank Stewart for providing access to a MiSeq, Neha Sarode and Josh Parris for technical help with MiSeq assay design and sequencing, Sandra Mendiola and Jason Chen for microscopy images, and Zev Oster for bioinformatic support.

\section{SUPPLEMENTARY MATERIAL}

The Supplementary Material for this article can be found online at: https://www.frontiersin.org/articles/10.3389/fmicb. 2021.719112/full\#supplementary-material

Supplementary Tables and Figures | This file contains all supplementary figures and tables, except for Supplementary Table 5.

Supplementary Table 5 | Pairwise distances between all 16s rRNA sequences derived from Anasa spp. samples.

Boucias, D. G., Garcia-Maruniak, A., Cherry, R., Lu, H., Maruniak, J. E., and Lietze, V.-U. (2012). Detection and characterization of bacterial symbionts in the Heteropteran, Blissus insularis. FEMS Microbiol. Ecol. 82, 629-641. doi: 10.1111/j.1574-6941.2012.01433.x

Bretz, F., Hothorn, T., and Westfall, P. (2010). Multiple Comparisons Using R. Boca Raton, FL: Chapman and Hall.

Bruton, B. D., Fletcher, J., Pair, S. D., Shaw, M., and Sittertz-Bhatkar, H. (1998). Association of a phloem-limited bacterium with yellow vine disease in cucurbits. Plant Dis. 82, 512-520. doi: 10.1094/PDIS.1998.82.5.512

Bruton, B. D., Mitchell, F., Fletcher, J., Pair, S. D., Wayadande, A., Melcher, U., et al. (2003). Serratia marcescens, a phloem-colonizing, squash bug-transmitted bacterium: causal agent of cucurbit yellow vine disease. Plant Dis. 87, 937-944. doi: 10.1094/PDIS.2003.87.8.937

Chuche, J., Auricau-Bouvery, N., Danet, J.-L., and Thiéry, D. (2016). Use the insiders: could insect facultative symbionts control vector-borne plant diseases? J. Pest Sci. 90, 51-68. doi: 10.1007/s10340-016-0782-3

Cook, C. A., and Neal, J. J. (1999). Feeding behavior of larvae of Anasa tristis (Heteroptera: Coreidae) on pumpkin and cucumber. Environ. Entomol. 28, 173-177. doi: 10.1093/ee/28.2.173 
Couret, J., Huynh-Griffin, L., Antolic-Soban, I., Acevedo-Gonzalez, T. S., and Gerardo, N. M. (2019). Even obligate symbioses show signs of ecological contingency: impacts of symbiosis for an invasive stinkbug are mediated by host plant context. Ecol. Evol. 9, 9087-9099. doi: 10.1002/ece3.5454

Crotti, E., Balloi, A., Hamdi, C., Sansonno, L., Marzorati, M., Gonella, E., et al. (2012). Microbial symbionts: a resource for the management of insect-related problems. Microb. Biotechnol. 5, 307-317. doi: 10.1111/j.1751-7915.2011.00312. $\mathrm{x}$

Dobritsa, A. P., and Samadpour, M. (2016). Transfer of eleven species of the genus Burkholderia to the genus Paraburkholderia and proposal of Caballeronia gen. nov. to accommodate twelve species of the genera Burkholderia and Paraburkholderia. Int. J. Syst. Evol. Microbiol. 66, 2836-2846. doi: 10.1099/ijsem. 0.001065

Dobritsa, A. P., and Samadpour, M. (2019). Reclassification of Burkholderia insecticola as Caballeronia insecticola comb. nov. and reliability of conserved signature indels as molecular synapomorphies. Int. J. Syst. Evol. Microbiol. 69, 2057-2063. doi: 10.1099/ijsem.0.003431

Douglas, A. E. (2007). Symbiotic microorganisms: untapped resources for insect pest control. Trends Biotechnol. 25, 338-342. doi: 10.1016/j.tibtech.2007.06.003

Edgar, R. C. (2004). MUSCLE: multiple sequence alignment with high accuracy and high throughput. Nucleic Acids Res. 32, 1792-1797. doi: 10.1093/nar/gkh340

Ehman, E. C., Johnson, G. B., Villanueva-meyer, J. E., Cha, S., Leynes, A. P., Eric, P., et al. (2018). Renewing Felsenstein's phylogenetic bootstrap in the era of Big Data. Nature 556, 452-456.

Faeth, S. H., and Fagan, W. F. (2002). Fungal endophytes: common host plant symbionts but uncommon mutualists. Integr. Comp. Biol. 42, 360-368. doi: $10.1093 / \mathrm{icb} / 42.2 .360$

Fukatsu, T., and Hosokawa, T. (2002). Capsule-transmitted gut symbiotic bacterium of the Japanese common plataspid stinkbug, Megacopta punctatissima. Appl. Environ. Microbiol. 68, 389-396. doi: 10.1128/AEM. 68.1.389-396.2002

Garcia, J. R., Laughton, A. M., Malik, Z., Parker, B. J., Trincot, C., Birnbaum, S. S. L., et al. (2014). Partner associations across sympatric broad-headed bug species and their environmentally acquired bacterial symbionts. Mol. Ecol. 23, 1333-1347. doi: 10.1111/mec.12655

Gerardo, N. M., and Parker, B. J. (2014). Mechanisms of symbiont-conferred protection against natural enemies: an ecological and evolutionary framework. Curr. Opin. Insect Sci. 4, 8-14. doi: 10.1016/j.cois.2014.08.002

Gonella, E., Pajoro, M., Marzorati, M., Crotti, E., Mandrioli, M., Pontini, M., et al. (2015). Plant-mediated interspecific horizontal transmission of an intracellular symbiont in insects. Sci. Rep. 5:15811. doi: 10.1038/srep15811

Gordon, E. R. L., McFrederick, Q., and Weirauch, C. (2016). Phylogenetic evidence for ancient and persistent environmental symbiont reacquisition in Largidae (Hemiptera: Heteroptera). Appl. Environ. Microbiol. 82, 7123-7133. doi: 10. 1128/AEM.02114-16

Guindon, S., Dufayard, J. F., Lefort, V., Anisimova, M., Hordijk, W., and Gascuel, O. (2010). New algorithms and methods to estimate maximum-likelihood phylogenies: assessing the performance of PhyML 3.0. Syst. Biol. 59, 307-321. doi: 10.1093/sysbio/syq010

Haine, E. R. (2008). Symbiont-mediated protection. Proc. R. Soc. B Biol. Sci. 275, 353-361. doi: 10.1098/rspb.2007.1211

Hosokawa, T., Kikuchi, Y., Shimada, M., and Fukatsu, T. (2007). Obligate symbiont involved in pest status of host insect. Proc. R. Soc. B Biol. Sci. 274, 1979-1984. doi: 10.1098/rspb.2007.0620

Itoh, H., Aita, M., Nagayama, A., Meng, X. Y., Kamagata, Y., Navarro, R., et al. (2014). Evidence of environmental and vertical transmission of Burkholderia symbionts in the oriental chinch bug, Cavelerius saccharivorus (Heteroptera: Blissidae). Appl. Environ. Microbiol. 80, 5974-5983. doi: 10.1128/AEM.0108714

Itoh, H., Hori, T., Sato, Y., Nagayama, A., Tago, K., Hayatsu, M., et al. (2018). Infection dynamics of insecticide-degrading symbionts from soil to insects in response to insecticide spraying. ISME J. 12, 909-920. doi: 10.1038/s41396-0170021-9

Itoh, H., Jang, S., Takeshita, K., Ohbayashi, T., Ohnishi, N., Meng, X. Y., et al. (2019). Host-symbiont specificity determined by microbe-microbe competition in an insect gut. Proc. Natl. Acad. Sci. U.S.A. 116, 22673-22682. doi: 10.1073/pnas.1912397116
Kikuchi, Y., and Fukatsu, T. (2014). Live imaging of symbiosis: spatiotemporal infection dynamics of a GFP-labelled Burkholderia symbiont in the bean bug Riptortus pedestris. Mol. Ecol. 23, 1445-1456. doi: 10.1111/mec.12479

Kikuchi, Y., Hayatsu, M., Hosokawa, T., Nagayama, A., Tago, K., and Fukatsu, T. (2012). Symbiont-mediated insecticide resistance. Proc. Natl. Acad. Sci. U.S.A. 109, 8618-8622. doi: 10.1073/pnas.1200231109

Kikuchi, Y., Hosokawa, T., and Fukatsu, T. (2007). Insect-microbe mutualism without vertical transmission: a stinkbug acquires a beneficial gut symbiont from the environment every generation. Appl. Environ. Microbiol. 73, 43084316. doi: 10.1128/AEM.00067-07

Kikuchi, Y., Hosokawa, T., and Fukatsu, T. (2011a). An ancient but promiscuous host-symbiont association between Burkholderia gut symbionts and their heteropteran hosts. ISME J. 5, 446-460. doi: 10.1038/ismej.2010.150

Kikuchi, Y., Hosokawa, T., and Fukatsu, T. (2011b). Specific developmental window for establishment of an insect-microbe gut symbiosis. Appl. Environ. Microbiol. 77, 4075-4081. doi: 10.1128/AEM.00358-11

Kikuchi, Y., Meng, X.-Y., and Fukatsu, T. (2005). Gut symbiotic bacteria of the genus Burkholderia in the broad-headed bugs Riptortus clavatus and Leptocorisa chinensis (Heteroptera: Alydidae). Appl. Environ. Microbiol. 71, 4035-4043. doi: 10.1128/AEM.71.7.4035-4043.2005

Kim, J. K., Jang, H. A., Won, Y. J., Kikuchi, Y., Han, S. H., Kim, C.-H., et al. (2014). Purine biosynthesis-deficient Burkholderia mutants are incapable of symbiotic accommodation in the stinkbug. ISME J. 8, 552-563. doi: 10.1038/ismej.2013. 168

Kim, J. K., Lee, H. J., Kikuchi, Y., Kitagawa, W., Nikoh, N., Fukatsu, T., et al. (2013a). Bacterial cell wall synthesis gene uppP is required for Burkholderia colonization of the stinkbug gut. Appl. Environ. Microbiol. 79, 4879-4886. doi: 10.1128/AEM.01269-13

Kim, J. K., Lee, J. B., Huh, Y. R., Jang, H. A., Kim, C.-H., Yoo, J. W., et al. (2015). Burkholderia gut symbionts enhance the innate immunity of host Riptortus pedestris. Dev. Comp. Immunol. 53, 265-269. doi: 10.1016/j.dci.2015.07.006

Kim, J. K., Won, Y. J., Nikoh, N., Nakayama, H., Han, S. H., Kikuchi, Y., et al. (2013b). Polyester synthesis genes associated with stress resistance are involved in an insect-bacterium symbiosis. Proc. Natl. Acad. Sci. U.S.A. 110, E2381-E2389. doi: 10.1073/pnas.1303228110/-/DCSupplemental

Kinosita, Y., Kikuchi, Y., Mikami, N., Nakane, D., and Nishizaka, T. (2017). Unforeseen swimming and gliding mode of an insect gut symbiont, Burkholderia sp. RPE64, with wrapping of the flagella around its cell body. ISME J. 12, 838-848. doi: 10.1038/s41396-017-0010-z

Klein, J. P., and Moeschberger, M. L. (2003). Survival Analysis: Techniques for Censored and Truncated Data. New York, NY: Springer.

Kozich, J. J., Westcott, S. L., Baxter, N. T., Highlander, S. K., and Schloss, P. D. (2013). Development of a dual-index sequencing strategy and curation pipeline for analyzing amplicon sequence data on the MiSeq illumina sequencing platform. Appl. Environ. Microbiol. 79, 5112-5120. doi: 10.1128/AEM.01043-13

Lane, D. (1991). "16S/23S rRNA sequencing," in Nucleic Acid Techniques in Bacterial Systematics, eds E. Stackebrandt, and M. Goodfellow (New York, NY: John Wiley and Sons), 125-175.

Lee, J. B., Park, K.-E., Lee, S. A., Jang, S. H., Eo, H. J., Jang, H. A., et al. (2017). Gut symbiotic bacteria stimulate insect growth and egg production by modulating hexamerin and vitellogenin gene expression. Dev. Comp. Immunol. 69, 12-22. doi: 10.1016/j.dci.2016.11.019

Lefort, V., Longueville, J. E., and Gascuel, O. (2017). SMS: smart model selection in PhyML. Mol. Biol. Evol. 34, 2422-2424. doi: 10.1093/molbev/msx149

Lemoine, F., Correia, D., Lefort, V., Doppelt-Azeroual, O., Mareuil, F., CohenBoulakia, S., et al. (2019). NGPhylogeny.fr: new generation phylogenetic services for non-specialists. Nucleic Acids Res. 47, W260-W265. doi: 10.1093/ nar/gkz303

Mendiola, S. Y., Civitello, D. J., and Gerardo, N. M. (2020). An integrative approach to symbiont-mediated vector control for agricultural pathogens. Curr. Opin. Insect Sci. 39, 57-62. doi: 10.1016/j.cois.2020.02.007

Mitsuhashi, J. (2002). Invertebrate Tissue Culture Methods. Berlin: Springer.

Moran, N. A. (2006). Symbiosis. Curr. Biol. 16, R866-R871. doi: 10.1016/j.cub. 2006.09.019

Neal, J. J. (1993). Xylem transport interruption by Anasa tristis feeding causes Cucurbita pepo to wilt. Entomol. Exp. Appl. 69, 195-200. doi: 10.1111/j.15707458.1993.tb01741.x/full 
Nechols, J. R. (1987). Voltinism, seasonal reproduction, and diapause in the squash bug (Heteroptera: Coreidae) in Kansas. Environ. Entomol. 16, 269-273. doi: 10.1093/ee/16.1.269

Nishino, T., Hosokawa, T., Meng, X.-Y., Koga, R., Moriyama, M., and Fukatsu, T. (2021). Environmental acquisition of gut symbiotic bacteria in the saw-toothed stinkbug, Megymenum gracilicorne (Hemiptera: Pentatomoidea: Dinidoridae). Zool. Sci. 38, 213-222. doi: 10.2108/zs200163

O'Fallon, B. (2008). Population structure, levels of selection, and the evolution of intracellular symbionts. Evolution 62, 361-373. doi: 10.1111/j.1558-5646.2007. 00289.x

Ohbayashi, T., Futahashi, R., Terashima, M., Barrière, Q., Lamouche, F., Takeshita, K., et al. (2019a). Comparative cytology, physiology and transcriptomics of Burkholderia insecticola in symbiosis with the bean bug Riptortus pedestris and in culture. ISME J. 13, 1469-1483. doi: 10.1038/s41396-019-0361-8

Ohbayashi, T., Itoh, H., Lachat, J., Kikuchi, Y., and Mergaert, P. (2019b). Burkholderia gut symbionts associated with European and Japanese populations of the dock bug Coreus marginatus (Coreoidea: Coreidae). Microbes Environ. 34, 219-222. doi: 10.1264/jsme2.ME19011

Ohbayashi, T., Takeshita, K., Kitagawa, W., Nikoh, N., Koga, R., Meng, X.-Y., et al. (2015). Insect's intestinal organ for symbiont sorting. Proc. Natl. Acad. Sci. U.S.A. 112, E5179-E5188. doi: 10.1073/pnas.1511454112

Olivier-Espejel, S., Sabree, Z. L., Noge, K., and Becerra, J. X. (2011). Gut microbiota in nymph and adults of the giant mesquite gug (Thasus neocalifornicus) (Heteroptera: Coreidae) is dominated by Burkholderia acquired De Novo every generation. Environ. Entomol. 40, 1102-1110. doi: 10.1603/EN10309

R Core Team (2013). R: A Language and Environment for Statistical Computing. Vienna: R Foundation for Statistical Computing.

Ravenscraft, A., Thairu, M. W., Hansen, A. K., and Hunter, M. S. (2020). Continent-scale sampling reveals fine-scale turnover in a beneficial bug symbiont. Front. Microbiol. 11:1276. doi: 10.3389/fmicb.2020.01276

Salem, H., Florez, L., Gerardo, N., and Kaltenpoth, M. (2015). An out-of-body experience: the extracellular dimension for the transmission of mutualistic bacteria in insects. Proc. R. Soc. B Biol. Sci. 282:20142957. doi: 10.1098/rspb. 2014.2957

Schloss, P. D., Westcott, S. L., Ryabin, T., Hall, J. R., Hartmann, M., Hollister, E. B., et al. (2009). Introducing mothur: open-source, platform-independent, community-supported software for describing and comparing microbial communities. Appl. Environ. Microbiol. 75, 7537-7541. doi: 10.1128/AEM. 01541-09

Su, Q., Pan, H., Liu, B., Chu, D., Xie, W., Wu, Q., et al. (2013). Insect symbiont facilitates vector acquisition, retention, and transmission of plant virus. Sci. Rep. 3:1367. doi: 10.1038/srep01367

Sudakaran, S., Retz, F., Kikuchi, Y., Kost, C., and Kaltenpoth, M. (2015). Evolutionary transition in symbiotic syndromes enabled diversification of phytophagous insects on an imbalanced diet. ISME J. 9, 2587-2604. doi: 10. 1038/ismej.2015.75

Takeshita, K., and Kikuchi, Y. (2020). Genomic comparison of insect gut symbionts from divergent Burkholderia subclades. Genes (Basel) 11:744. doi: 10.3390/ genes 11070744

Takeshita, K., Matsuura, Y., Itoh, H., Navarro, R., Hori, T., Sone, T., et al. (2015). Burkholderia of plant-beneficial group are symbiotically associated with bordered plant bugs (Heteroptera: Pyrrhocoroidea: Largidae). Microbes Environ. 30, 321-329. doi: 10.1264/jsme2.ME1 5153

Therneau, T. M. (2013). A Package for Survival Analysis in S. Available online at: http://cran.r-project.org/package=survival

Toju, H., and Fukatsu, T. (2010). Diversity and infection prevalence of endosymbionts in natural populations of the chestnut weevil: relevance of local climate and host plants. Mol. Ecol. 20, 853-868. doi: 10.1111/j.1365-294X.2010. 04980.x

Weiss, B., and Aksoy, S. (2011). Microbiome influences on insect host vector competence. Trends Parasitol. 27, 514-522. doi: 10.1016/j.pt.2011.0 5.001

Xu, Y., Buss, E. A., and Boucias, D. G. (2016a). Culturing and characterization of gut symbiont Burkholderia spp. from the southern chinch bug, Blissus insularis (Hemiptera: Blissidae). Appl. Environ. Microbiol. 82, 3319-3330. doi: 10.1128/ AEM.00367-16

Xu, Y., Buss, E. A., and Boucias, D. G. (2016b). Environmental transmission of the gut symbiont Burkholderia to phloem-feeding Blissus insularis. PLoS One 11:e0161699. doi: 10.1371/journal.pone.0161699

Conflict of Interest: The authors declare that the research was conducted in the absence of any commercial or financial relationships that could be construed as a potential conflict of interest.

Publisher's Note: All claims expressed in this article are solely those of the authors and do not necessarily represent those of their affiliated organizations, or those of the publisher, the editors and the reviewers. Any product that may be evaluated in this article, or claim that may be made by its manufacturer, is not guaranteed or endorsed by the publisher.

Copyright (c) 2021 Acevedo, Fricker, Garcia, Alcaide, Berasategui, Stoy and Gerardo. This is an open-access article distributed under the terms of the Creative Commons Attribution License (CC BY). The use, distribution or reproduction in other forums is permitted, provided the original author(s) and the copyright owner(s) are credited and that the original publication in this journal is cited, in accordance with accepted academic practice. No use, distribution or reproduction is permitted which does not comply with these terms. 